\title{
The impact of HIV clinical pharmacists on HIV treatment outcomes: a systematic review
}

\author{
This article was published in the following Dove Press journal: \\ Patient Preference and Adherence \\ 4 April 2012 \\ Number of times this article has been viewed
}

\author{
Parya Saberi \\ Betty J Dong ${ }^{2}$ \\ Mallory $\bigcirc$ Johnson' \\ Ruth M Greenblatt ${ }^{2}$ \\ Jennifer M Cocohoba ${ }^{2}$ \\ 'Department of Medicine, \\ ${ }^{2}$ Department of Clinical Pharmacy, \\ University of California, San Francisco, \\ CA, USA
}

Objective: Due to the rapid proliferation of human immunodeficiency virus (HIV) treatment options, there is a need for health care providers with knowledge of antiretroviral therapy intricacies. In a HIV multidisciplinary care team, the HIV pharmacist is well-equipped to provide this expertise. We conducted a systematic review to assess the impact of HIV pharmacists on HIV clinical outcomes.

Methods: We searched six electronic databases from January 1, 1980 to June 1, 2011 and included all quantitative studies that examined pharmacist's roles in the clinical care of HIVpositive adults. Primary outcomes were antiretroviral adherence, viral load, and $\mathrm{CD}_{4}^{+}$cell count and secondary outcomes included health care utilization parameters, antiretroviral modifications, and other descriptive variables.

Results: Thirty-two publications were included. Despite methodological limitation, the involvement of HIV pharmacists was associated with statistically significant adherence improvements and positive impact on viral suppression in the majority of studies.

Conclusion: This systematic review provides evidence of the beneficial impact of HIV pharmacists on HIV treatment outcomes and offers suggestions for future research.

Keywords: pharmacist, HIV/AIDS, clinical, adherence, impact

\section{Introduction}

Since the first reported cases of AIDS in $1981^{1}$ and the emergence of the global human immunodeficiency virus (HIV) pandemic, the field of antiretroviral (ARV) therapy has undergone extraordinary changes and continues to witness dramatic progress. The availability of over two dozen distinct ARVs, providing more tolerable and safer agents, and the ability to tailor ARV regimens to individual patients, demonstrates the substantial advancement in the field and the heightened understanding and expertise that is required to minimize drug interactions, contraindications, and adverse effects. The increased incidence of comorbidities in the aging HIV-positive population demands close monitoring and a keen awareness of the interplay between various therapies, the transmission of drug resistant viruses requires knowledge of ARV regimen selection, and the need for life-long therapy necessitates high ARV adherence and long-term follow-up. Therefore, the HIV clinical pharmacist has emerged as an indispensable member of the HIV multidisciplinary care team.

Publications as early as 1991 have described the involvement of pharmacists in clinics and hospital teams caring for HIV-positive individuals. ${ }^{2-4}$ These and other studies $^{5,6}$ demonstrate the importance of the pharmacist's medication expertise and involvement in the multidisciplinary care team. Most recently, Horberg et $\mathrm{al}^{7}$ examined 
the components of the HIV multidisciplinary care team that are associated with the greatest increases in ARV adherence. The involvement of clinical pharmacists represented the first branch of the regression tree (signifying the component of the care team with the greatest impact on adherence) and the presence of clinical pharmacists resulted in statistically significant improvements in adherence in conjunction with any multidisciplinary care team member.

Given the extensive history and indications that clinical pharmacists may be particularly valuable in the medical care of HIV-positive individuals, we conducted a systematic review to assess the contributions of HIV pharmacists on HIV clinical outcomes, including ARV adherence and virologic and immunologic parameters. The purpose of this review was to systematically evaluate the research conducted to date and identify gaps in our knowledge regarding the impact of HIV clinical pharmacists in the clinical care of those living with HIV/AIDS.

\section{Methods Objective}

The primary objective of this systematic review was to evaluate the impact of clinical pharmacists on HIV clinical outcomes. Primary outcomes included ARV adherence, $\mathrm{HIV}$ viral load suppression, and $\mathrm{CD}_{4}^{+}$cell count. Secondary outcomes consisted of health care utilization parameters, antiretroviral modifications, and other descriptive variables.

\section{Data sources}

We searched PubMed, EMBASE ${ }^{\circledR}$, Cochrane Library, Web of Science ${ }^{\circledR}$, BIOSIS Previews, and PsycINFO ${ }^{\circledR}$ from 1980 (or the respective date of inception of each database) until June 1, 2011. Additionally, we conducted a manual search by screening the references of pertinent articles and identifying any additional relevant publications that were not previously included. Due to incomplete data presentation in conference abstracts, we did not include conference proceedings and abstracts in this review.

\section{Search strategy}

We conducted our search strategy in the style of Cochrane Highly Sensitive Search Strategy to identify all relevant published studies. ${ }^{8}$ We included randomized and nonrandomized controlled trials, before-after comparisons, historically controlled trials, cohort studies, cross-sectional studies, case-control studies, and descriptive studies, as well as appropriate medical subject headings (MeSH) terms, and a wide range of relevant search terms in all databases.
The detailed search strategy used for PubMed can be found in Table 1. This strategy was modified as appropriate for use in other databases.

\section{Inclusion and exclusion criteria}

We included all studies that examined the role of a pharmacist in the clinical care of HIV-infected adults. Studies were divided into two broad categories based on the researchers' prespecified intentions in examining the impact of pharmacists. The first category encompassed "intervention studies"; these studies included HIV pharmacist activities that were part of a study protocol and were only implemented for the purpose of research upon receipt of informed consent. The second category included studies of "clinical care activities"; defined as studies which examined pharmacist actions that were taken as part of routine patient care and which examined specific outcomes (eg, the impact of an existing pharmacist adherence clinic on adherence). These clinical care activities were not conducted for the purpose of research and would have occurred regardless of the study. The reason for this classification was to assess the rigor of the research and the evolution of publications regarding HIV clinical pharmacists over time. Studies that did not include details of the pharmacist's involvement, but specifically mentioned any pharmacist participation were included. Multifactorial interventions or clinical care activities were included as long as at least one factor clearly indicated pharmacist contributions.

We also classified the pharmacist role as being central or peripheral to the study objectives. The pharmacist role was considered "central" in studies that were specifically designed to examine the influence of pharmacists on the care of HIV-positive individuals. Studies where the role of the pharmacist was "peripheral" were those in which the pharmacist was involved in carrying out the study objectives, but the research was not designed to examine the sole impact of the pharmacist.

We did not include studies that exclusively assessed pharmacist's ability to provide HIV prevention services or studies that only assessed pharmacy operations (such as medication stock, home delivery, medication packaging, etc). Studies were included without regard to the location where they were conducted, but were limited to English language publications. Research that was purely qualitative was excluded.

\section{Review methods and data abstraction}

Using EndNote software package (X5.0.1; Thomson Reuters, New York, NY) relevant studies were located 
Table I Example of search strategy used in PubMed

\begin{tabular}{|c|c|}
\hline Search \# & PubMed search terms \\
\hline \#7 & Search \#5 AND \#6 \\
\hline \multirow[t]{8}{*}{ \#6 } & Search randomized controlled trial[pt] OR controlled clinical trial[pt] OR randomized controlled trials[mh] OR random \\
\hline & allocation[mh] OR double-blind method[mh] OR single-blind method[mh] OR clinical trial[pt] OR clinical trials[mh] OR "clinical \\
\hline & trial”[tw] OR ((singl*[tw] OR doubl*[tw] OR trebl*[tw] OR tripl*[tw]) AND (mask*[tw] OR blind*[tw])) OR Placebos[mh] OR \\
\hline & placebo*[tw] OR random*[tw] OR nonrandomi*[tw] OR before after study[tw] OR time series[tw] OR "case control” $[\mathrm{tw}]$ OR \\
\hline & prospective*[tw] OR retrospective*[tw] OR cohort[tw] OR cross-section*[tw] OR research design[mh:noexp] OR comparative \\
\hline & study[pt] OR evaluation studies[pt] OR follow-up studies[mh] OR prospective studies[mh] OR controlled $[\mathrm{tw}] \mathrm{OR}$ control[tw] OR \\
\hline & volunteer*[tw] OR longitud*[tw] OR descripti*[tiab] OR study[tiab] OR evaluat*[tiab] OR “odds ratio"[tw] OR "hazard ratio"[tw] \\
\hline & OR “relative risk”[tw] OR “risk ratio”[tw] OR AOR[tiab] OR RRR[tiab] OR NNT[tiab] OR design*[tiab] \\
\hline \#5 & Search \#I AND \#2 AND \#3 AND \#4 \\
\hline \multirow[t]{6}{*}{ \#4 } & Search HAART[tiab] OR ART[tiab] OR ARV[tiab] OR ARVs[tiab] OR anti-retroviral*[tiab] OR antiretroviral*[tiab] OR "anti- \\
\hline & viral"[tiab] OR antiviral[tiab] OR "anti-HIV" OR antiHIV OR "Antiretroviral Therapy, Highly Active"[mh] OR "Anti-Retroviral \\
\hline & Agents" $[\mathrm{mh}]$ OR CD4[tw] OR immune[tw] OR immunolo*[tw] OR immunology[sh] OR lymphocyte[tw] OR CD4-Positive \\
\hline & T-Lymphocytes[mh] OR CD4 Lymphocyte Count[mh] OR CD4 count* OR "viral load" [tw] OR virol*[tw] OR viral[tw] OR \\
\hline & virology[sh] OR outcome OR outcomes OR prognosis OR “outcome and process assessment(health care)"[mh] OR th[sh:noexp] \\
\hline & OR dt[sh] OR effective*[tw] \\
\hline \multirow[t]{2}{*}{ \#3 } & Search adhere*[tiab] OR complian*[tiab] OR adhere*[tw] OR complian*[tw] OR Patient Compliance[mh] OR Medication \\
\hline & $\begin{array}{l}\text { Adherence }[\mathrm{mh}] \text { OR Counseling[mh] OR counsel*[tw] OR education }[\mathrm{tw}] \text { OR monitor*[tw] OR interven*[tw] OR self } \\
\text { administration[mh] }\end{array}$ \\
\hline \multirow[t]{3}{*}{$\# 2$} & Search pharmacist*[tiab] OR PharmD[tiab] OR “Pharm D”[tiab] OR pharmacy[tiab] OR pharmacies[tiab] OR pharmacists[mh] OR \\
\hline & pharmacy $[\mathrm{mh}]$ OR community pharmacy services $[\mathrm{mh}]$ OR medication therapy management $[\mathrm{mh}]$ OR pharmacy service, hospital[mh] \\
\hline & OR pharmaceutical services[mh:noexp] \\
\hline \multirow[t]{5}{*}{ \#I } & Search HIV Infections[mh] OR HIV[mh] OR HIV[tiab] OR HIV-I [tiab] OR HIV-2[tiab] OR HIV-I [tiab] OR HIV-2[tiab] OR HIV \\
\hline & infect*[tiab] OR human immunodeficiency virus[tiab] OR human immune deficiency virus[tiab] OR human immuno-deficiency \\
\hline & virus[tiab] OR ((human immun*) AND (deficiency virus[tiab])) OR acquired immunodeficiency syndrome[tiab] OR acquired \\
\hline & immune deficiency syndrome[tiab] OR acquired immuno-deficiency syndrome[tiab] OR ((acquired immun*) AND (deficiency \\
\hline & syndrome[tiab])) OR HIV/AIDS[tiab] OR “HIV AIDS”[tiab] OR “Sexually Transmitted Diseases, Viral”[mh] \\
\hline
\end{tabular}

in the above-mentioned data sources and duplicates and irrelevant articles were extracted by one author (PS). Two authors (PS, JC) independently read the remaining citations and identified eligible studies based on prespecified inclusion/exclusion criteria. All uncertainties and disagreements were arbitrated by a third author (BD). Using a data abstraction form, three authors (PS, JC, BD) summarized pertinent information from included articles and over $30 \%$ of all abstracted data was re-examined by another author to ensure data accuracy. We utilized the Cochrane guide for study assessment checklist to assign the study design to each included study. ${ }^{9}$

\section{Outcome variables}

The primary outcome of this review focused on the impact of the pharmacist on ARV adherence, HIV viral load, and $\mathrm{CD}_{4}^{+}$cell count. Secondary outcomes included change in the number of physician or emergency room visits, change in pill burden (ie, frequency of daily dosing or quantity of pills per day), cost effectiveness or any cost containment data, discontinuation or initiation of opportunistic infection prophylaxis or treatment, percentage of clinical care activities accepted by the attending physician or team, change in patients' or providers' HIV knowledge, impact on ARV drug resistance, and reports of the number of clinical care activities conducted by the pharmacist (eg, identification of dose errors, initiation/discontinuation/ consolidation of ARVs, adverse effect and drug interaction detection and management, resolution of medication adherence issues, and provision of drug information). Given the variability in assessment, analysis, and presentation of outcomes in identified studies, we were unable to conduct a meta-analysis.

\section{Results}

From 1545 search matches, 68 articles were assessed for eligibility and, of these, 36 were excluded because they were published in a language other than English $(n=3)$, were in abstract form $(n=11)$, were review articles $(n=3)$, were qualitative studies $(n=4)$, or were not regarding pharmacist clinical care activities or intervention $(n=15)$ (Figure 1). Thirty-two publications met our eligibility criteria and were included. ${ }^{10-41}$ Among these publications, 19 evaluated the primary outcomes of interest ${ }^{10-28}$ and 13 contained information on the secondary outcomes. ${ }^{29-41}$ Tables 2 and 3 summarize these studies. 


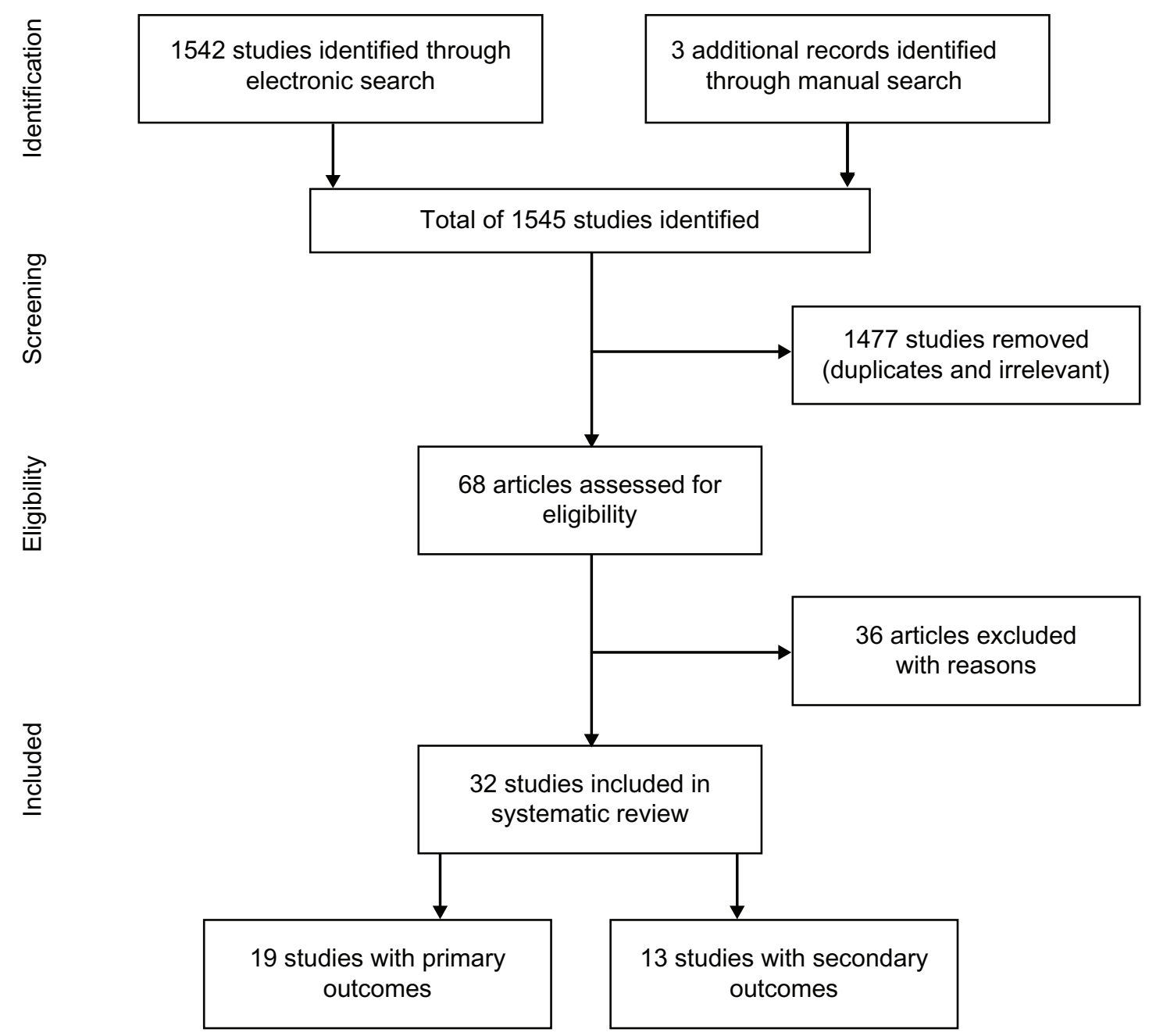

Figure I Selection process for study inclusion.

\section{Publications evaluating HIV clinical pharmacists' impact on primary outcomes}

These studies were published between 2000 and 2011 and were primarily conducted in the US (68\%). Observational cohort studies (32\%) and before-after comparisons (32\%) were the most common study designs. Baseline sample sizes ranged from 28 to 7018 (median $=64$ ); in studies that reported mean age, participant mean age ranged from 36 years to 49 years; and the percentage of male study participants ranged from $0 \%$ to $100 \%$ (median $=80 \%$ ). The percentage of participants who were Black ranged from $15 \%$ to $83 \%$ (median $=26 \%$; not stated in $32 \%$ of studies $)$; the proportion of White participants ranged from $12 \%$ to $71 \%$ (median $=52 \%$; not stated in $32 \%$ of studies); and the percentage of men who have sex with men (MSM) ranged from $0 \%$ to $70 \%$ (median $=51 \%$; not stated in $47 \%$ of studies). The pharmacist played a central role in the study objectives of $53 \%$ of included publications ${ }^{11,14,15,17,20,21,24,25,27,28}$ and $63 \%$ of studies examined the impact of pharmacist interventions (see Methods section for definition). ${ }^{10-13,15,17,19,20,22-24,26}$

The majority of the reviewed studies examined the impact of pharmacists in HIV ambulatory care clinic setting (63\%), ${ }^{10-12,15-21,25,28}$ followed by outpatient community pharmacies (26\%). ${ }^{14,22,24,26,27}$ The main pharmacist role was the provision of medication adherence counseling and tools for adherence improvement (including pill boxes, refill reminders, beepers, alarms, medication schedules, blister packs, medication diaries, etc). Other pharmacist activities included patient education (regarding dosing, adverse effects, drug interactions, medication storage, missed doses, adherence, methods of improving adherence, etc); ARV regimen selection; ARV initiation, discontinuation, and dose adjustment for renal/hepatic impairment; and monitoring for ARV adverse effects and drug interactions. 


\section{ARV adherence}

In the 18 studies that examined ARV adherence ${ }^{10-19,21-28}$ (adherence not assessed in March et $\mathrm{al}^{20}$ ), the most common method of adherence assessment was based on medication refill records $(56 \%)$, followed by patient self-report (33\%), and electronic drug monitoring using medication event monitoring systems (MEMS $\left.{ }^{\circledR}, 28 \%\right)$. Other less frequently used methods included pill count and therapeutic drug level monitoring. Approximately $78 \%$ of studies used only one adherence assessment method and $17 \%$ used two methods.

Among the 10 publications in which the pharmacist's role was central, ${ }^{11,14,15,17,20,21,24,25,27,28}$ adherence was compared between the pharmacist group versus a control group in eight studies; ${ }^{11,14,15,17,21,25,27,28}$ all of which found an association between assignment to the pharmacist group and improved adherence outcomes. Nine studies examined interventions or clinical care activities where the pharmacist had a peripheral role, ${ }^{10,12,13,16,18,19,22,23,26}$ among which five reported medication adherence outcomes by comparing the pharmacist group versus a control group..$^{13,16,18,22,26}$ Four of these studies reported a positive association between adherence and allocation to the pharmacist group ${ }^{13,16,22,26}$ and one showed no statistically significant difference between the two arms. ${ }^{18}$

Among 13 studies that compared adherence outcomes of a pharmacist-engaged study arm versus a control arm, ${ }^{11,13-18,21,22,24-26,28}$ nine reported percent ARV adherence as a continuous outcome in each group at the end of the follow-up period. ${ }^{11,13,16-18,21,24-26}$ In these studies, adherence in the pharmacist arm was $2 \%-59 \%($ median $=19 \%)$ higher as compared to the control arm. Four studies used other methods of comparison to present the impact of pharmacist care on adherence. ${ }^{14,15,22,28}$ Castillo et al, ${ }^{14}$ found that $14.7 \%$ more patients who obtained service from AIDS tertiary care hospital pharmacies had $>90 \%$ adherence compared to those with no pharmacist contact. Hirsch et al, ${ }^{22}$ found that $18.2 \%$ more patients receiving ARVs from pilot Medi-Cal pharmacies, featuring pharmacists with HIV training, had an adherence of $80 \%-120 \%$ in comparison to those not enrolled in this program. In a study by Henderson et al, ${ }^{28} 25 \%$ more patients had $>95 \%$ adherence after referral to the pharmacist-managed clinic versus prior to referral. Lastly, Levy et $\mathrm{al}^{15}$ reported that participants missed 1.2 fewer doses in the past 7 days after receipt of a pharmacist-provided adherence education session versus the period of observation prior to this intervention.

\section{HIV viral load}

Among the ten studies that assessed the central role of the pharmacist, ${ }^{11,14,15,17,20,21,24,25,27,28}$ nine examined viral load outcomes. ${ }^{11,14,15,17,20,21,25,27,28}$ In six of these studies, pharmacist involvement was associated with clinically or statistically significant viral load reductions or a greater proportion of maximal viral suppression, ${ }^{14,17,20,21,25,28}$ while in three, no association with pharmacist care was observed. ${ }^{11,15,27}$ The pharmacist assumed a peripheral role in nine studies, ${ }^{10,12,13,16,18,19,22,23,26}$ among which five reported virologic outcomes. ${ }^{12,13,18,19,23}$ In four of these studies, a favorable association was noted between viral load reduction and allocation to the pharmacist-involved study arm, ${ }^{12,13,18,23}$ whereas no relationship between virologic response and pharmacist care was reported by one study. ${ }^{19}$

\section{$\mathrm{CD}_{4}^{+}$cell count}

In the ten studies where a pharmacist played a central role, seven also assessed immunologic outcomes. ${ }^{11,15,17,20,21,25,27}$ Among these studies, two revealed an increase in $\mathrm{CD}_{4}^{+}$cell count related to receipt of pharmacist care ${ }^{20,25}$ and five showed no association. ${ }^{11,15,17,21,27}$ Of the nine studies in which the pharmacist had a peripheral role, only two reported immunologic outcomes $^{18,19}$ and in both no relationship was seen between the pharmacist arm versus the control arm.

\section{Other outcomes}

Among the ten studies investigating the pharmacist's central role, several reported other favorable outcomes, including an increase in adherence to clinic appointments and reductions in variables such as hospitalizations, ${ }^{11} \mathrm{ARV}$ toxicity scores, ${ }^{20}$ physician office visits, number of hospital days, emergency department visits, ${ }^{21}$ pill burden, and daily dosing frequency. ${ }^{25}$ Other outcomes in the nine studies where the pharmacist assumed a peripheral role included no changes in variables such as ARV adherence self-efficacy, ${ }^{13}$ retention on ARV at 12 months, ${ }^{18}$ and frequency of incident opportunistic infections. ${ }^{22,26}$ However, there were increases in the time on ARV therapy, ${ }^{18}$ improved appointment keeping, ${ }^{19}$ higher likelihood of remaining on $\mathrm{ARV}^{22,26}$ fewer contraindicated ARV regimens, ${ }^{22,26}$ and a higher cost in the study arm involving the pharmacist. ${ }^{19,22}$

\section{Publications evaluating HIV clinical pharmacists' impact on secondary outcomes}

These studies were published between 1992 and 2011 and $69 \%$ were conducted in the US. Approximately $80 \%$ of these studies were descriptive in nature. Baseline sample sizes 


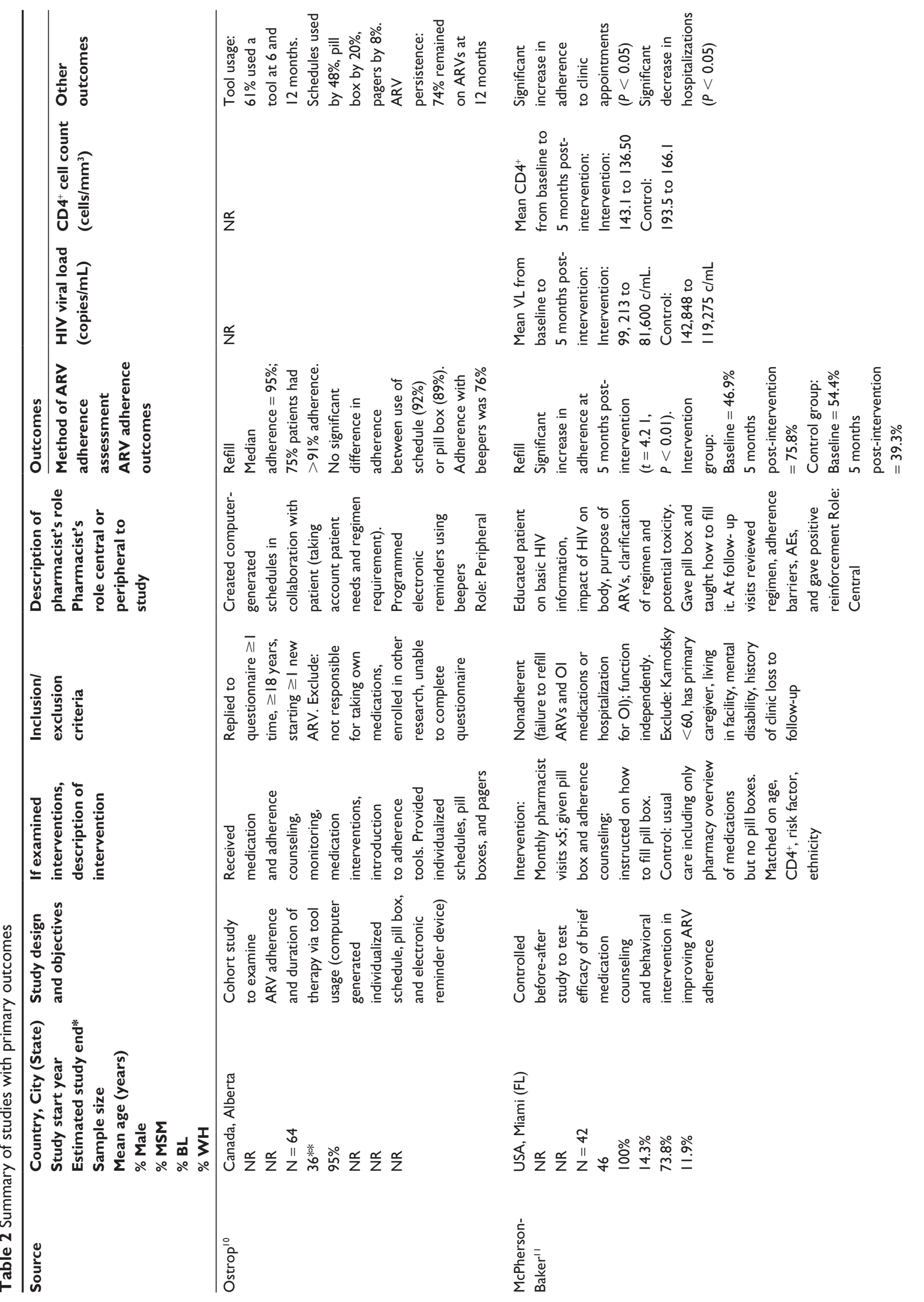




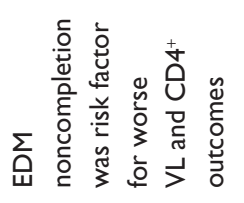

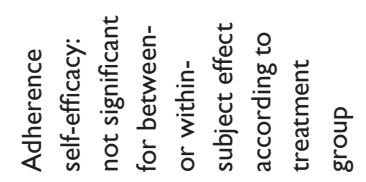

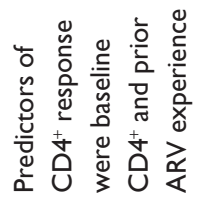

$\stackrel{\propto}{z}$

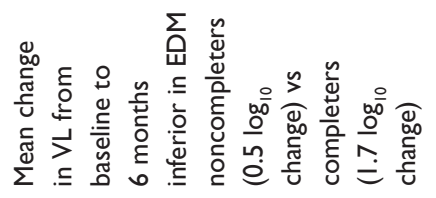

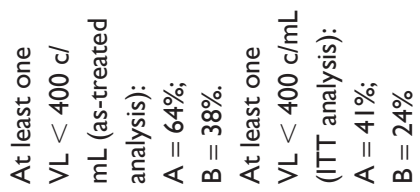

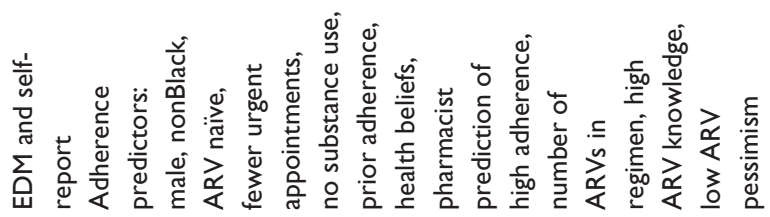

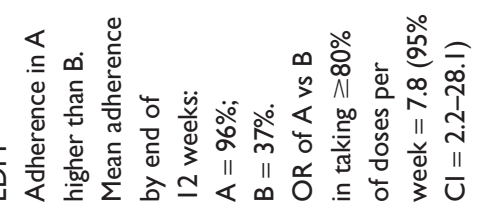

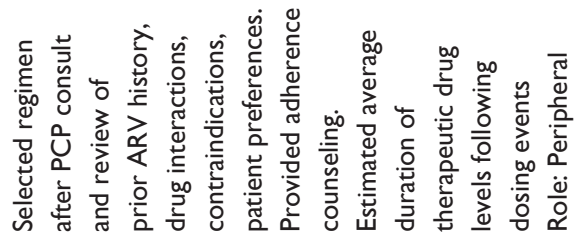

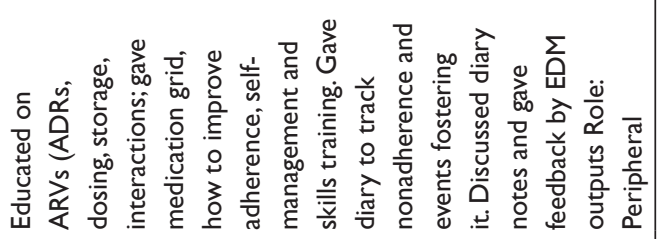

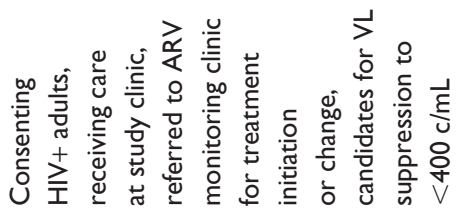

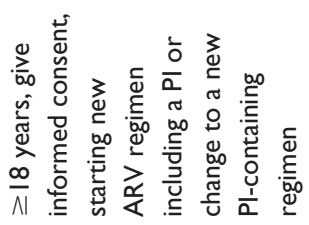

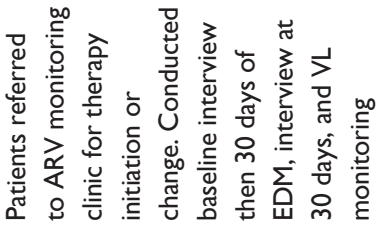

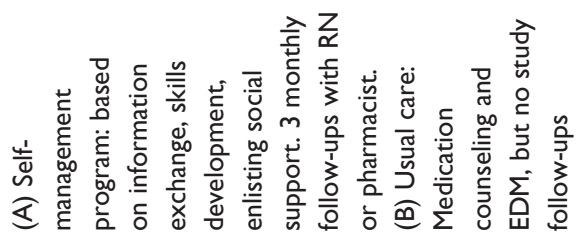

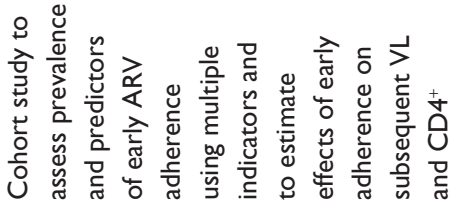

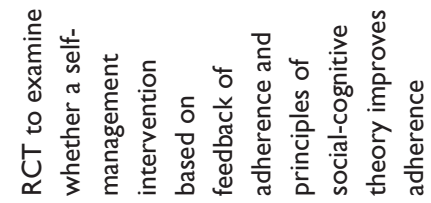

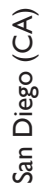

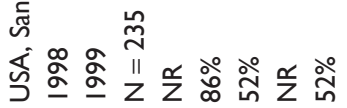

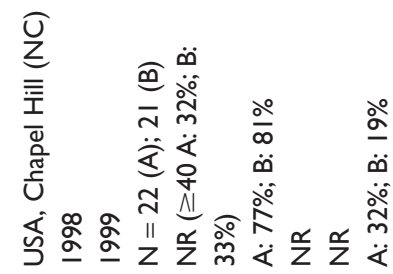

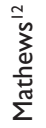




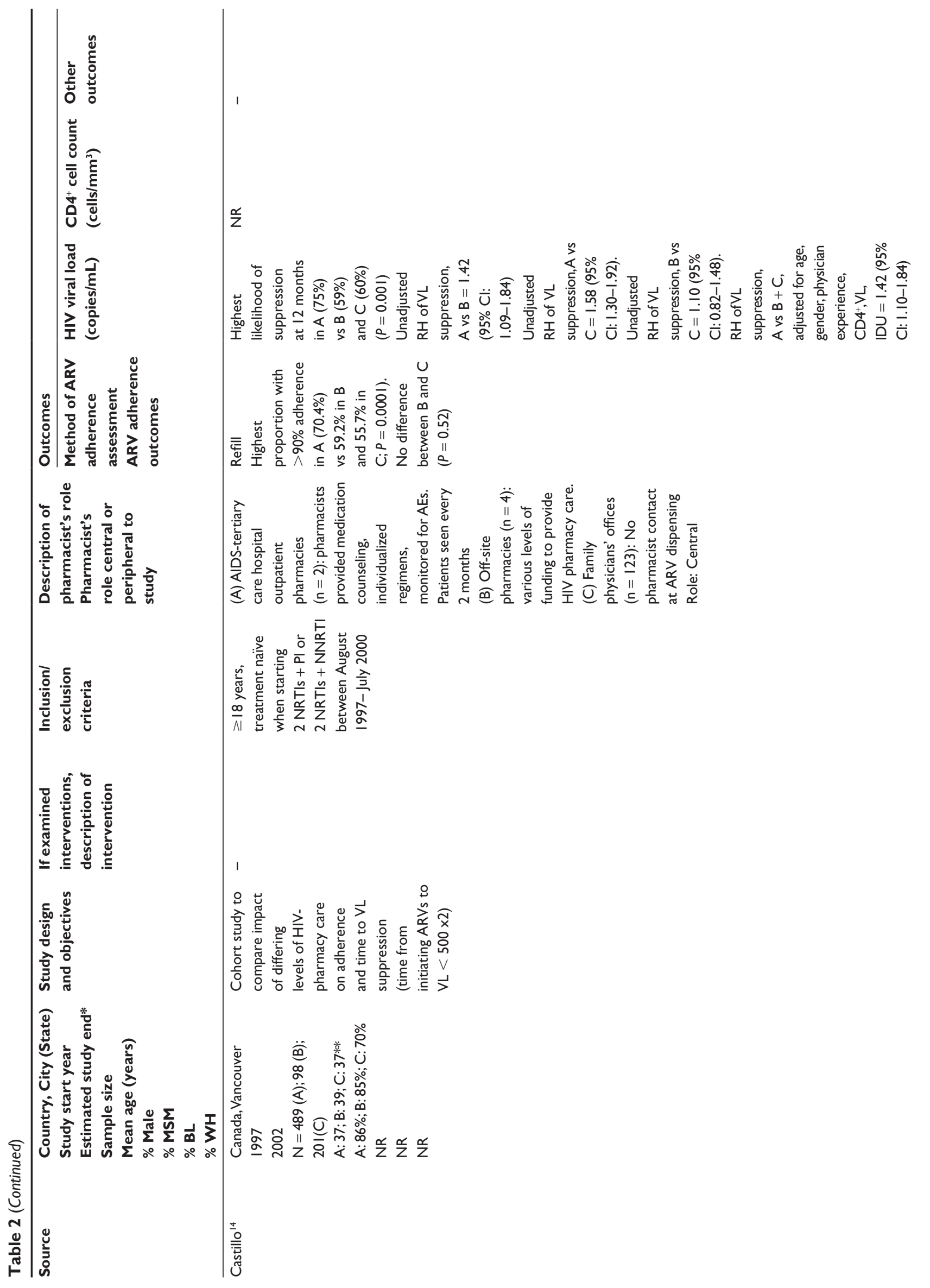



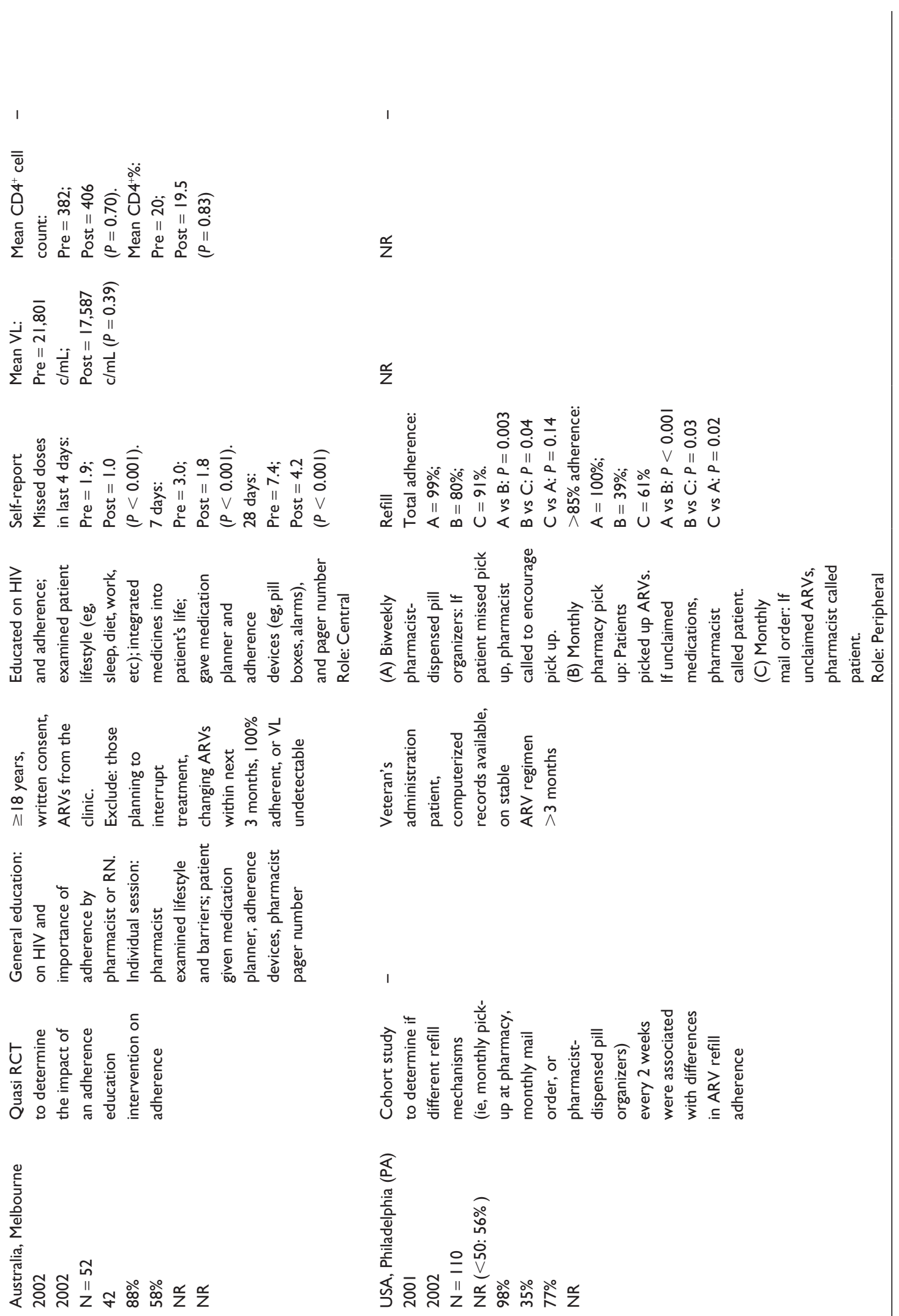

胥

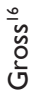




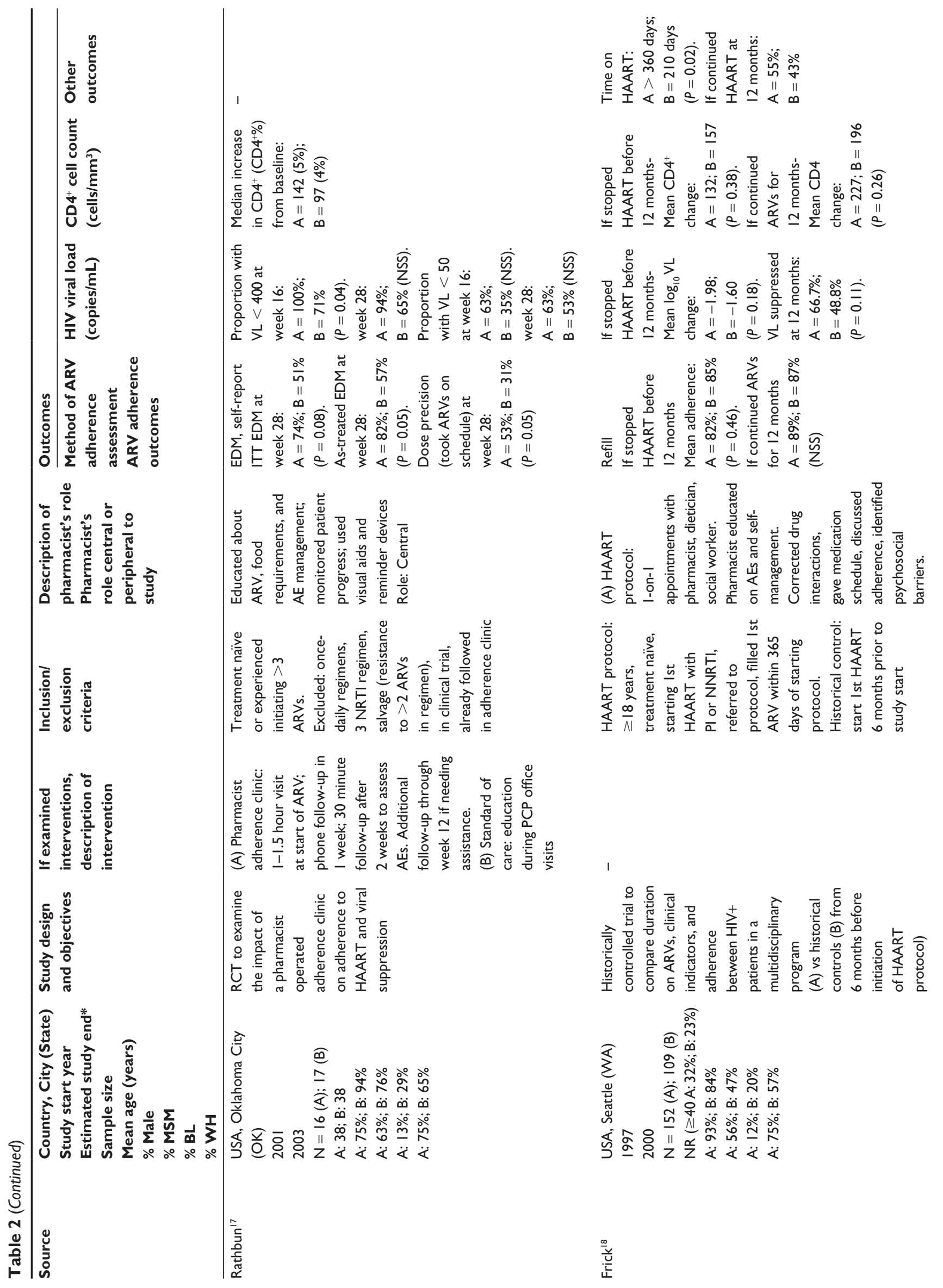



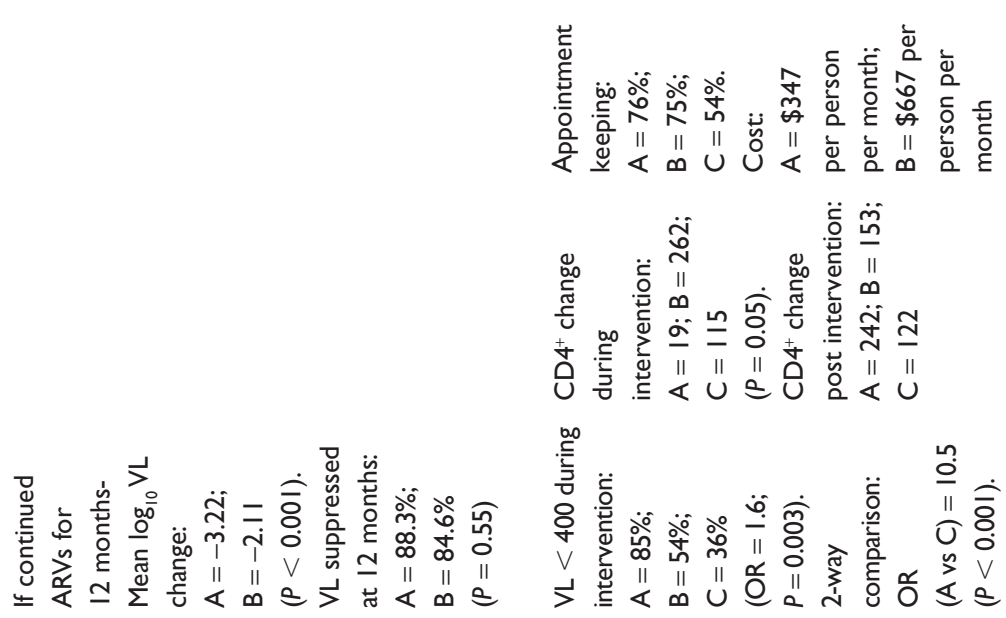

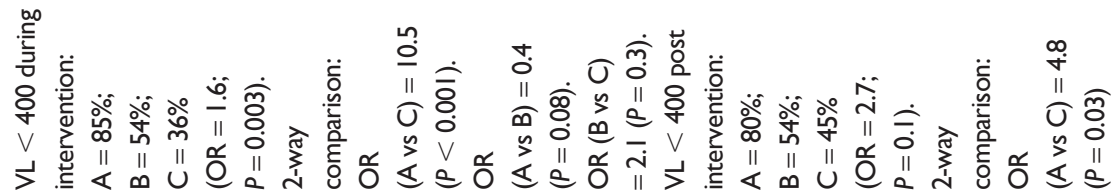

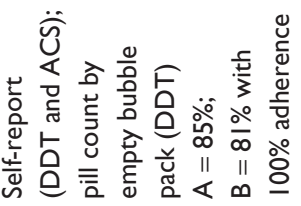
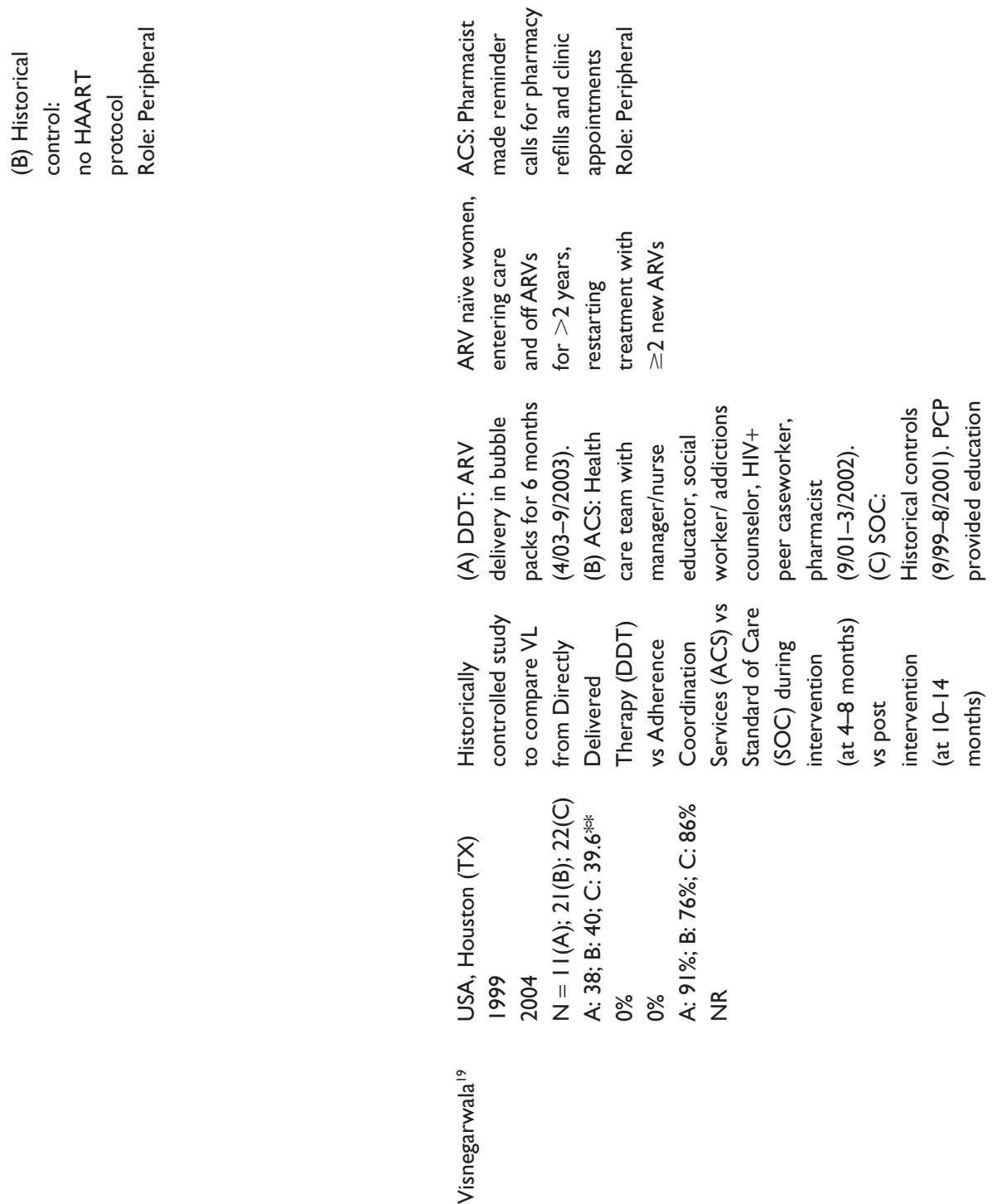


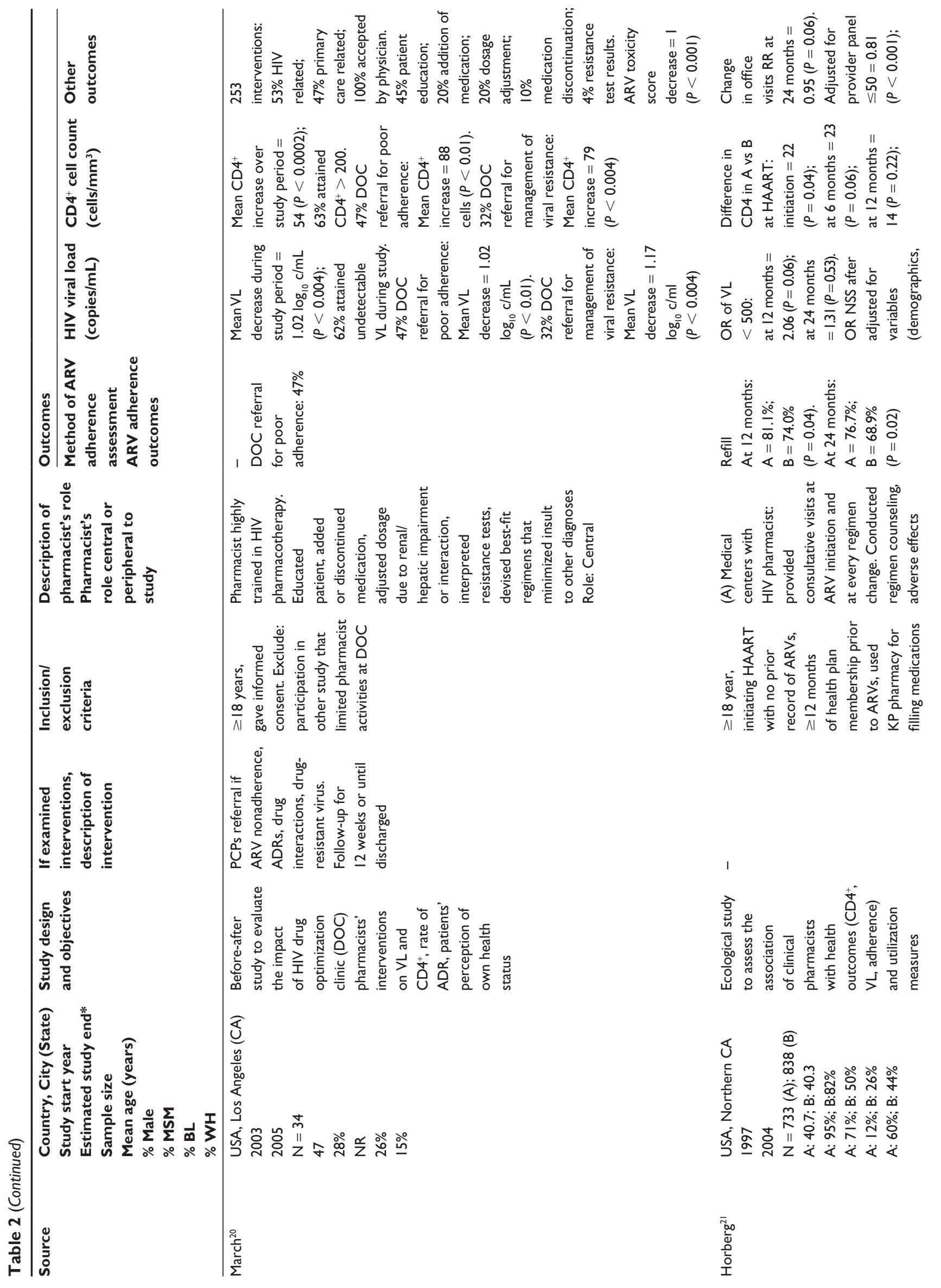




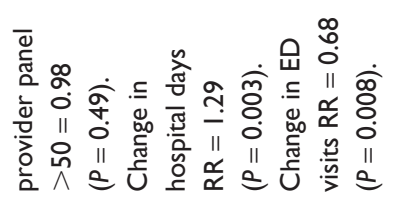

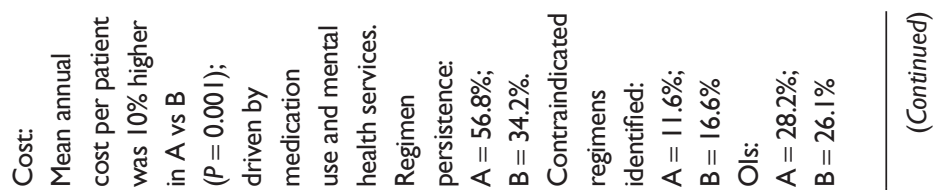

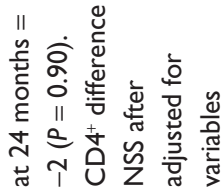

$\stackrel{\propto}{z}$

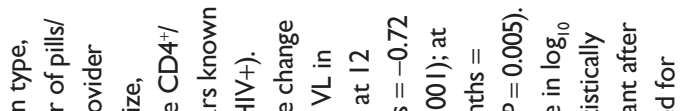

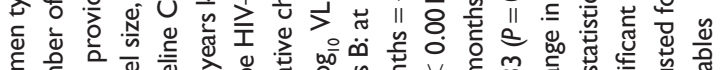

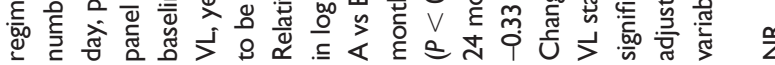

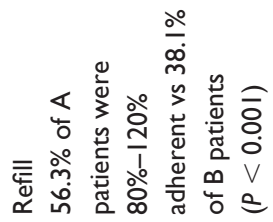

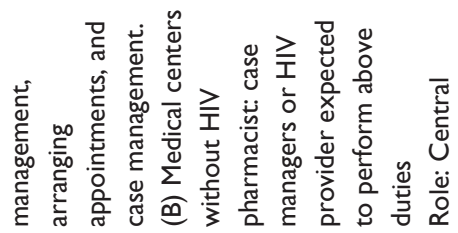

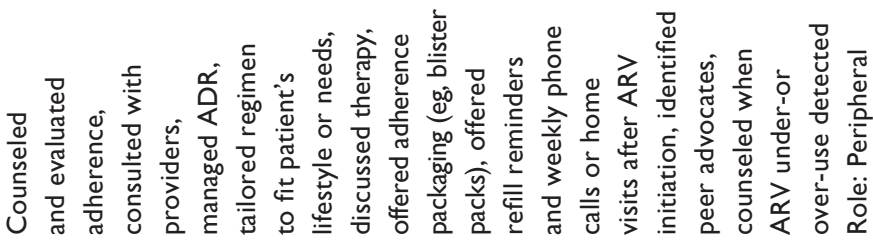

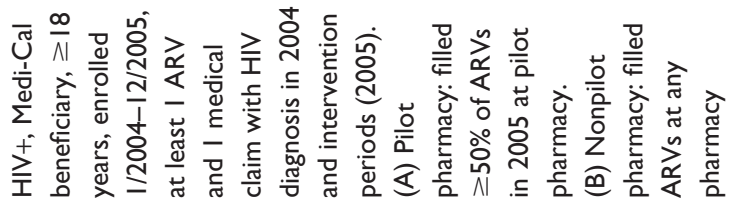

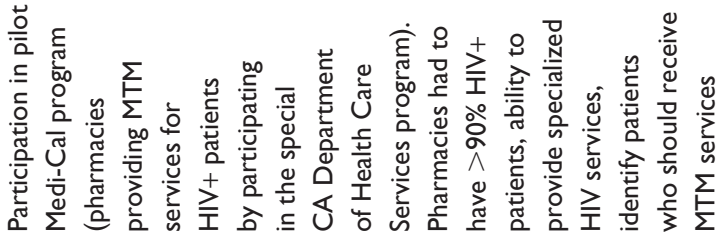

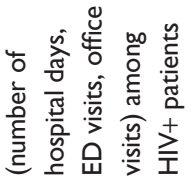

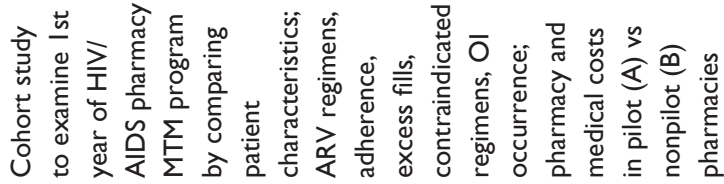

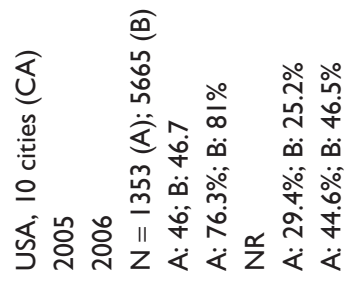

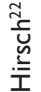




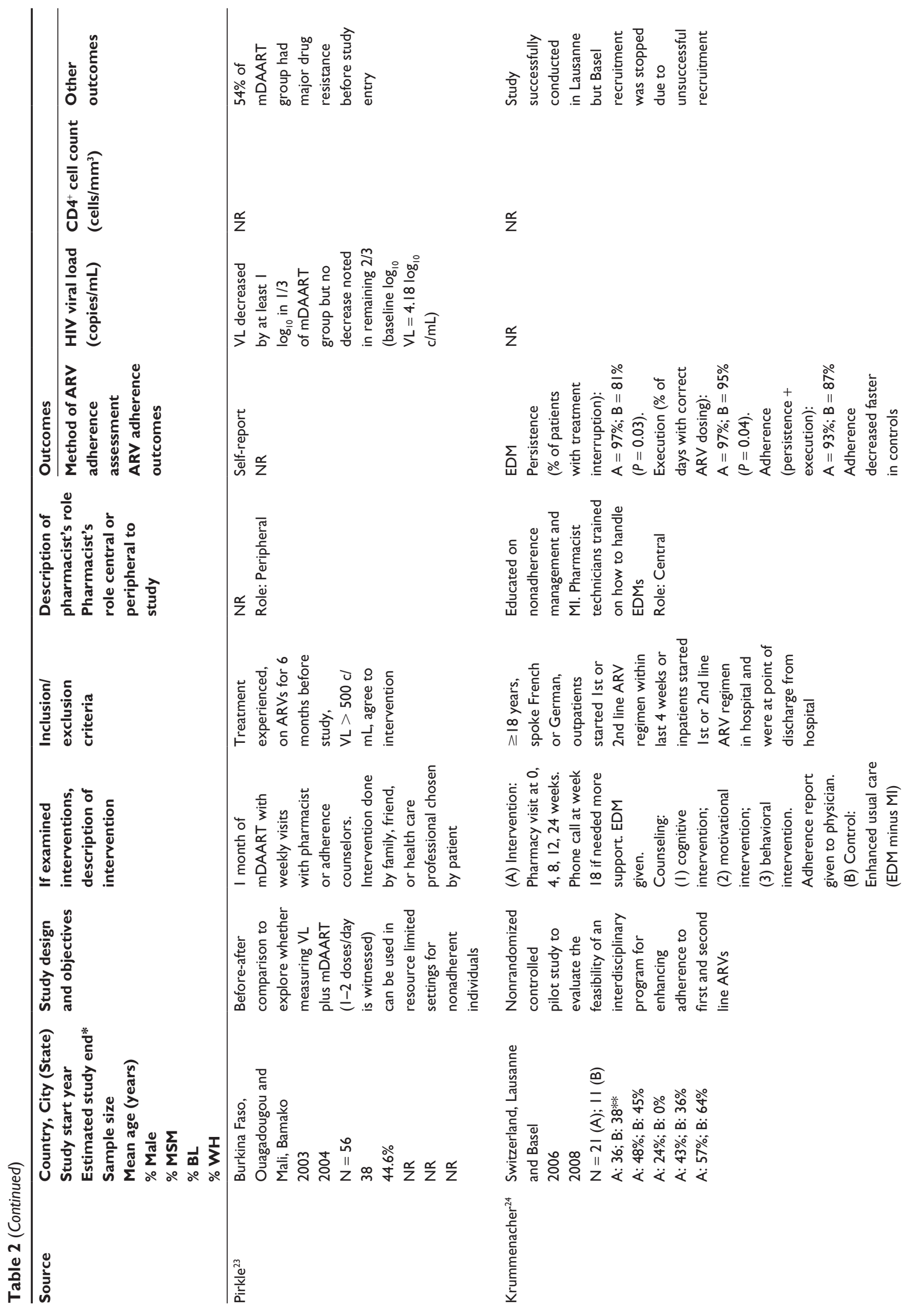




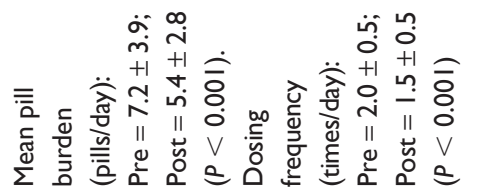

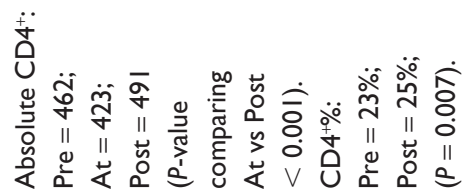

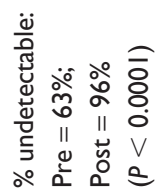

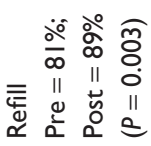

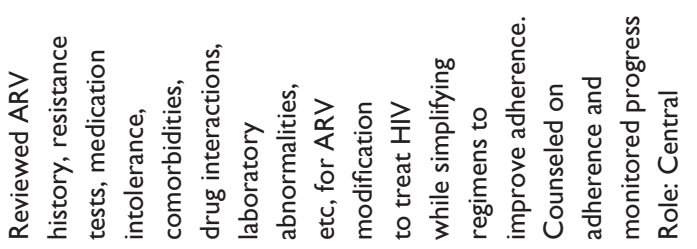

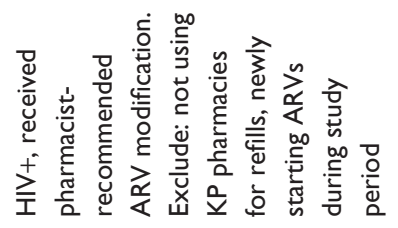

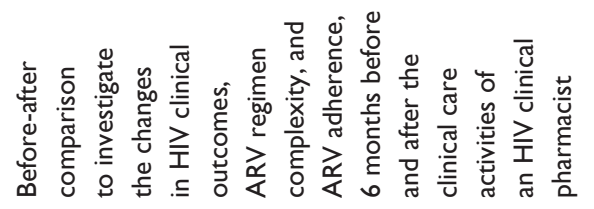

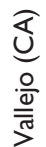

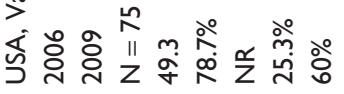

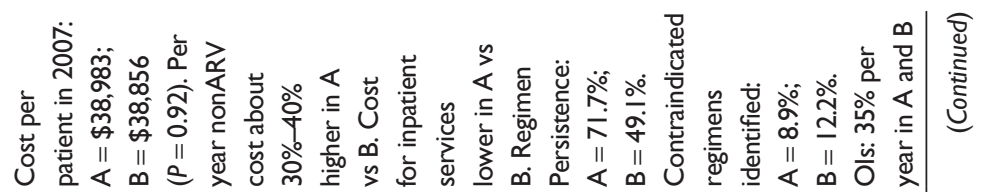

$\stackrel{\Re}{Z}$

$\stackrel{\alpha}{z}$

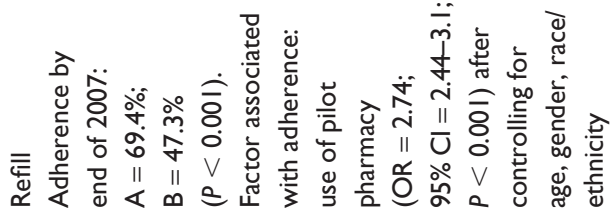

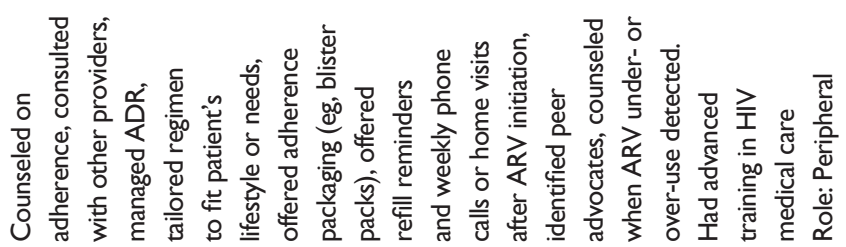

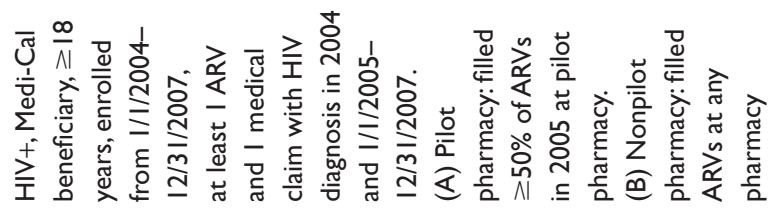

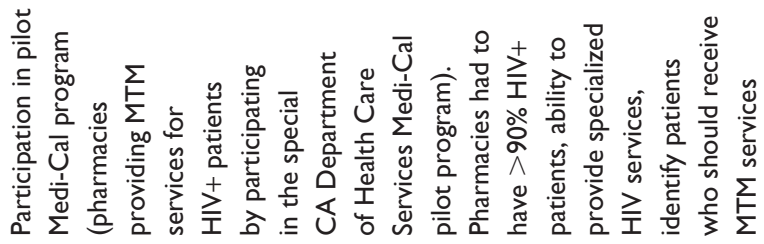

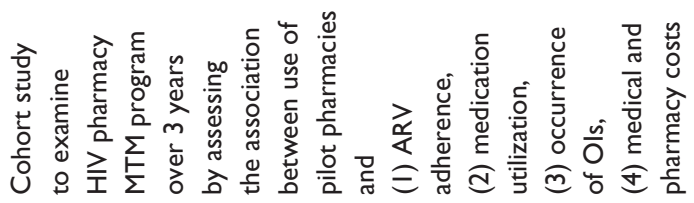

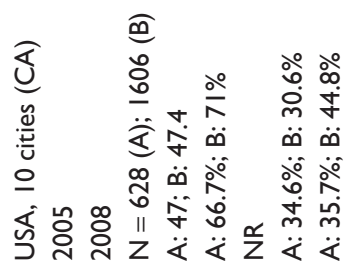

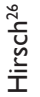




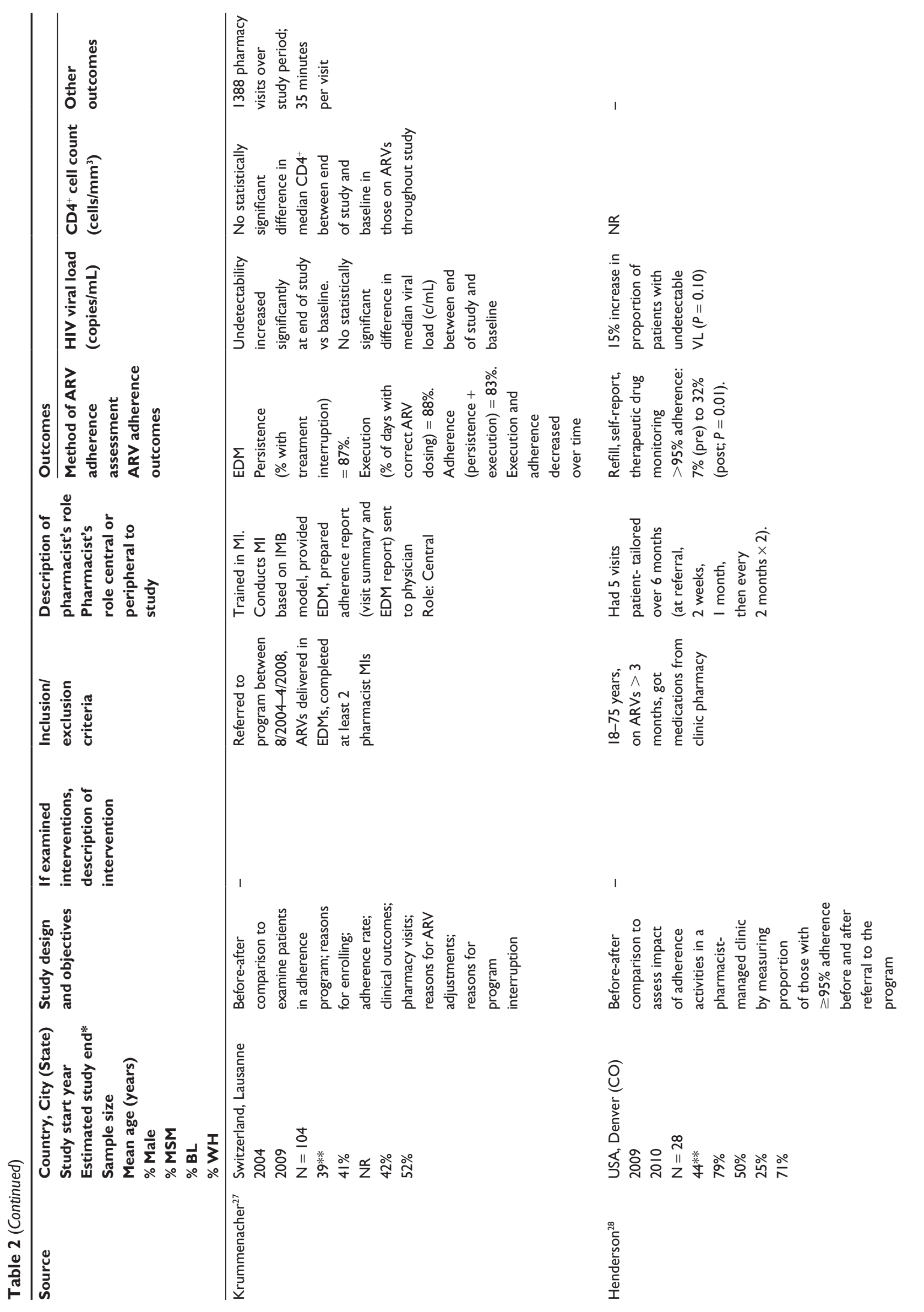




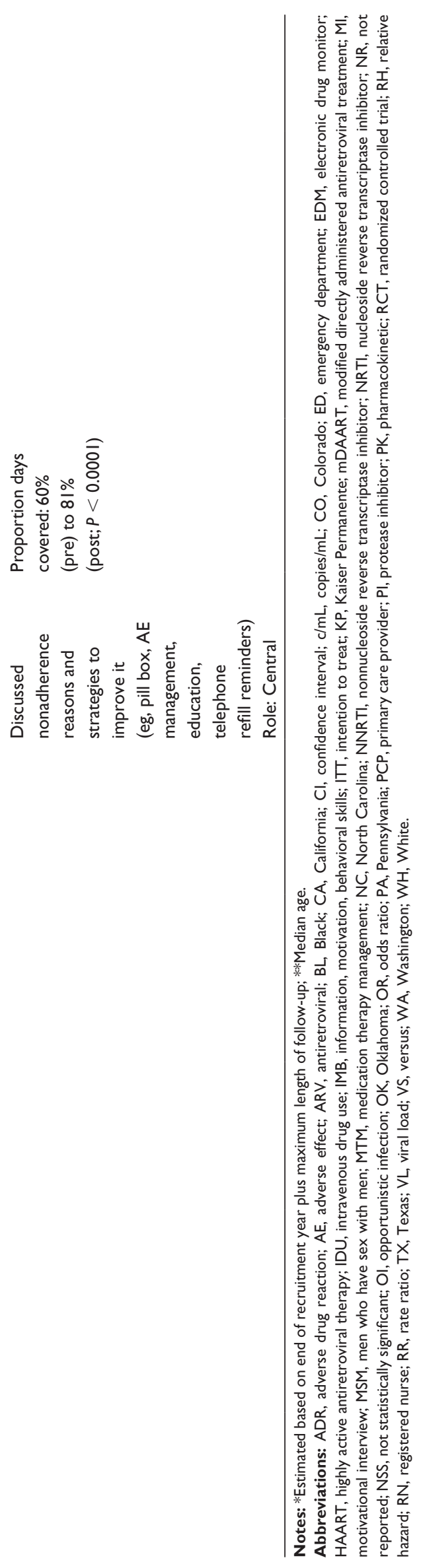

ranged from 31 to 285 (median $=70$ ); in studies reporting mean age, participant mean age ranged from 36 years to 65 years (age not stated in 38\% of studies); percentage of male study participants ranged from $49 \%$ to $100 \%$ (median $=71 \%$; not stated in $31 \%$ of studies). The percentage of participants who were Black ranged from $27 \%$ to $82 \%$ (median $=53 \%$; not stated in $69 \%$ of studies); proportion of participants who were White ranged from $18 \%$ to $53 \%$ (median $=20 \%$; not stated in $62 \%$ of studies); and percentage of MSM ranged from $6 \%$ to $26 \%$ (not stated in $85 \%$ of studies).

In $92 \%$ of these studies, the central role of a pharmacist was evaluated $\mathrm{d}^{29-38,40,41}$ and approximately $85 \%-100 \%$ of the pharmacists' suggestions were accepted by the physician or health care team. Sixty-nine percent of studies examined pharmacists' impact in the inpatient medical center setting ${ }^{30-32,34,37-41}$ and $23 \%$ assessed this role in the outpatient ambulatory care clinics. ${ }^{29,33,35}$ The clinical care activities performed by pharmacists in these reports included adjustments in drug doses, medication initiation/discontinuation, monitoring and prevention of drug interactions or adverse drug reactions, and the provision of drug information and medication counseling.

In one study, the researchers noted an improvement in the inpatient documentation of outpatient medications, a reduction in inappropriate discontinuation of outpatient medications, and an increase in ARV prescription accuracy for inpatients. ${ }^{40}$ Another study examined the benefits of pharmacists on the inpatient service and reported a substantial reduction in the length of time taken to correct an ARV error ${ }^{38}$ Conversely, in the only study that examined the effect of a pharmacist's interventions (see Methods for definition), the reduction in the number of drug interactions between patients whose physician received only their medication list was no different from those whose physician received both the medication list and the pharmacist's drug interaction notification and management suggestions. ${ }^{35}$

\section{Discussion}

In this systematic review, we evaluated the impact of HIV pharmacists on HIV clinical outcomes, health utilization measures, ARV modifications, and other descriptive variables. In all but one study, ${ }^{18}$ the involvement of an HIV pharmacist in patient care was associated with clinically and statistically significant improvements in ARV adherence. The majority of reviewed studies also indicated that HIV pharmacist's care was associated with greater viral load suppression. Evidence of any influence of pharmacists on immunologic outcomes was unclear and attenuated, which 


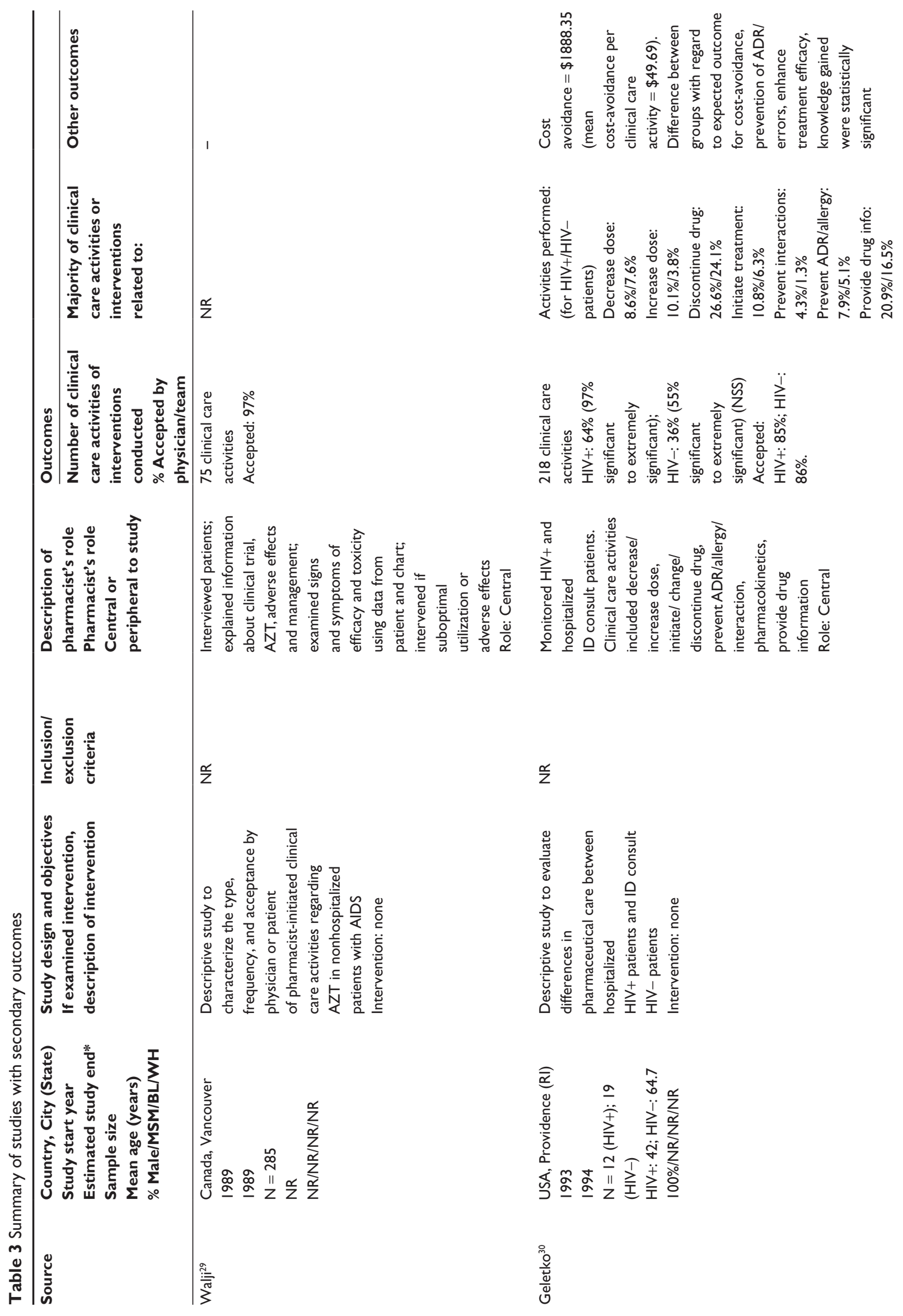




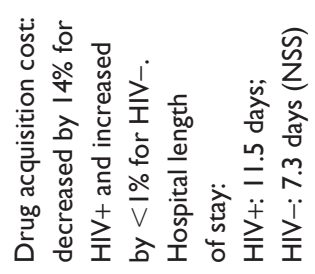

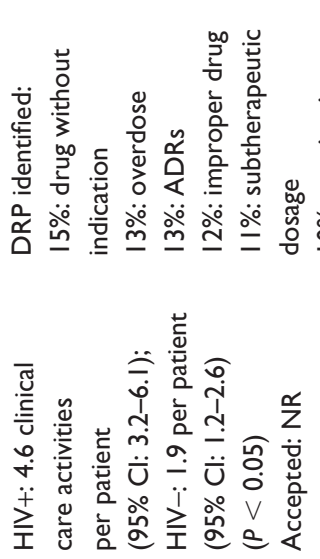

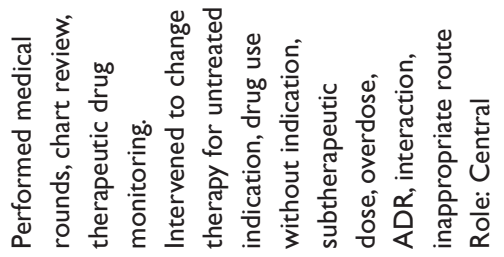

$\stackrel{\propto}{z}$

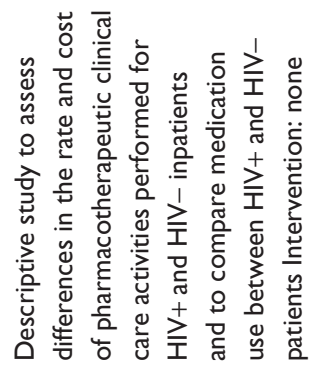

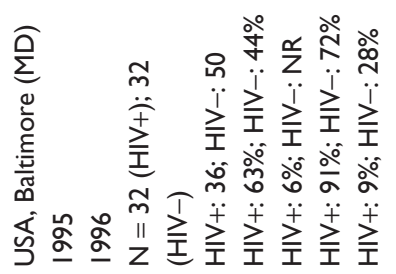

产 $\stackrel{o}{z}$

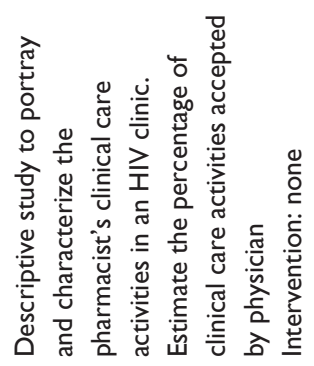

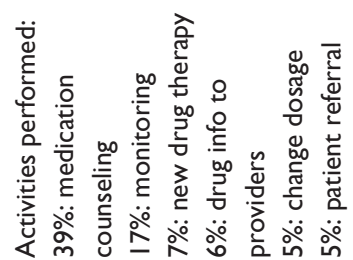

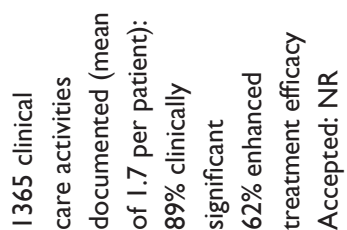
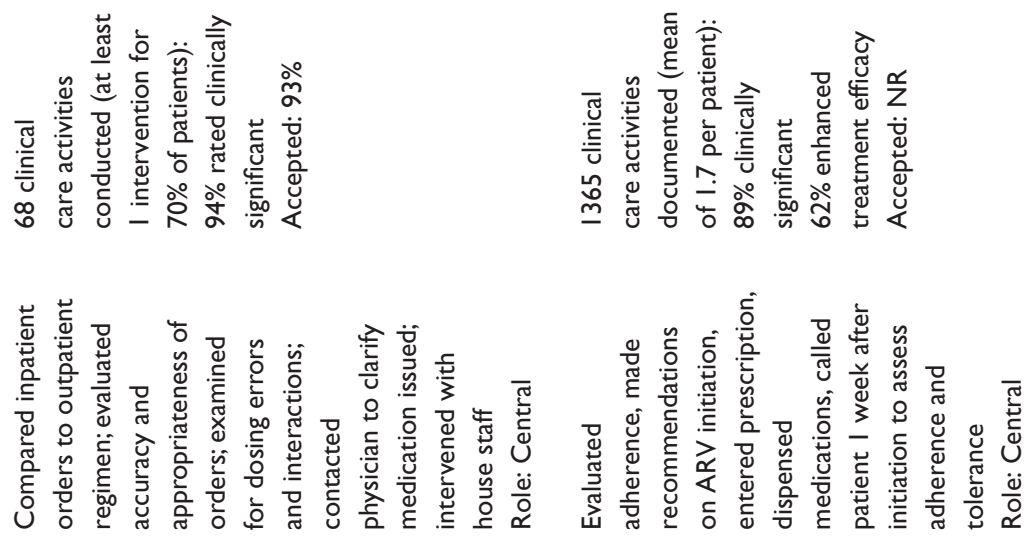

$\stackrel{\infty}{z}$
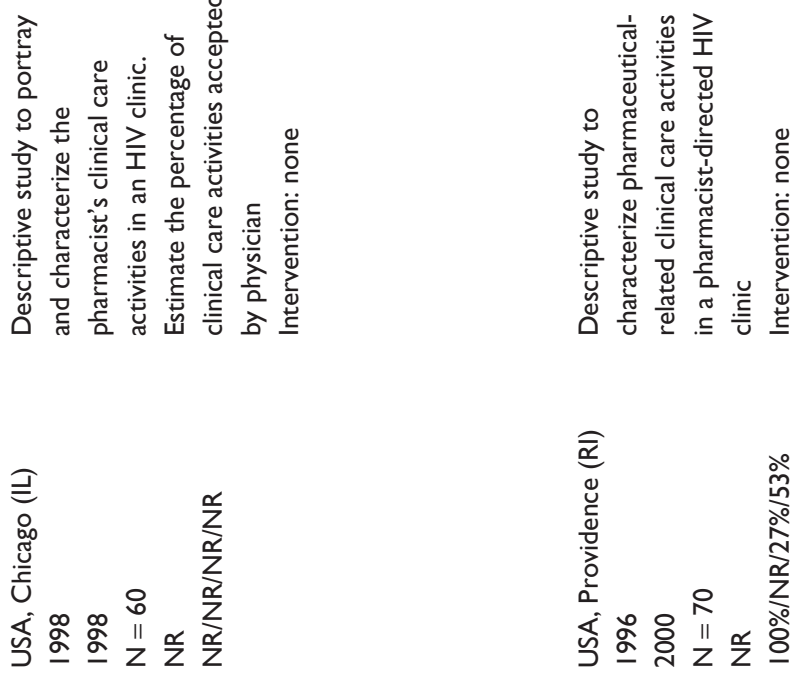

㠃 


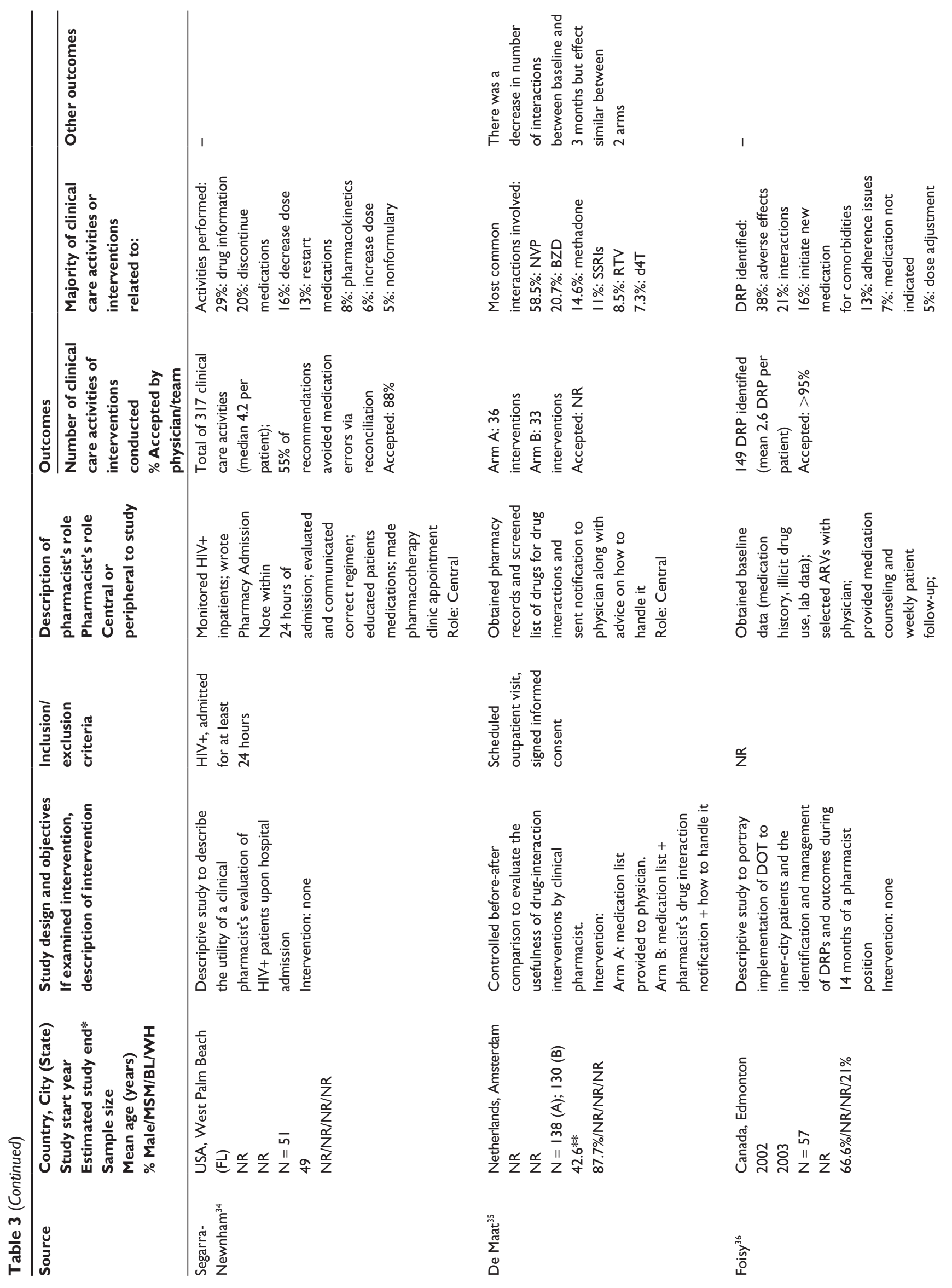


兌

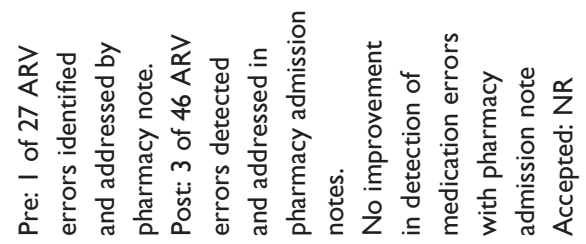

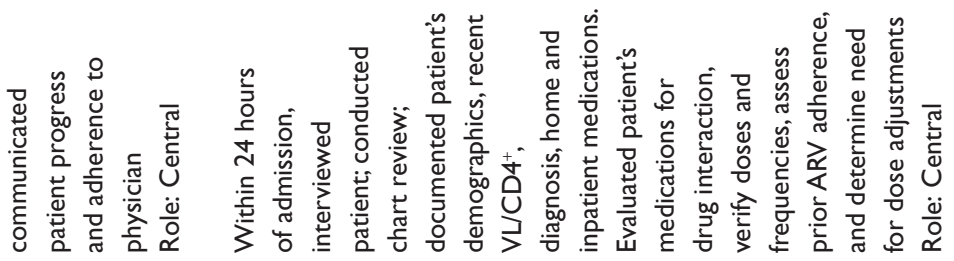
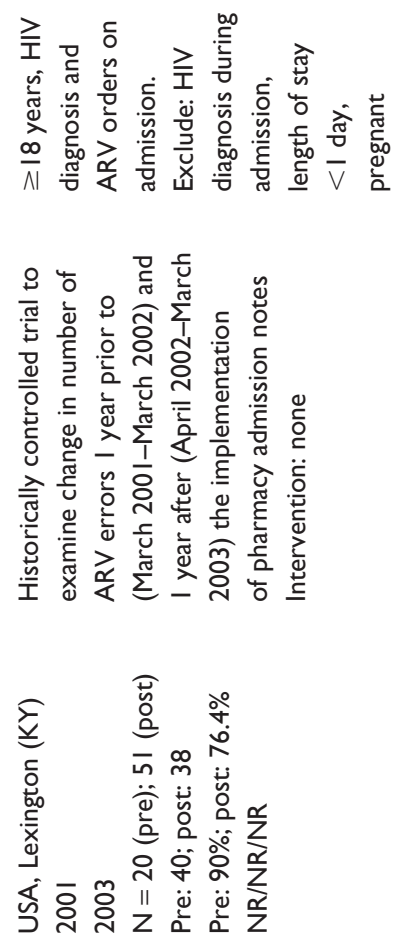

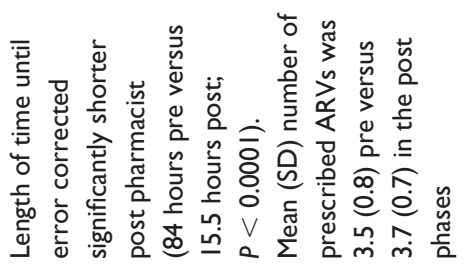

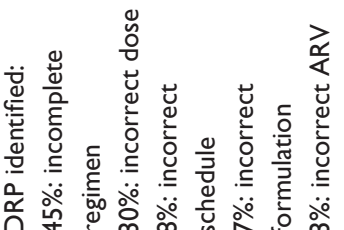

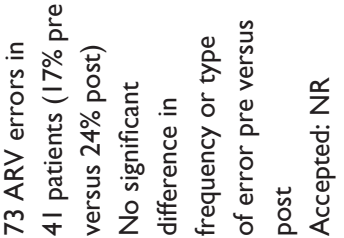

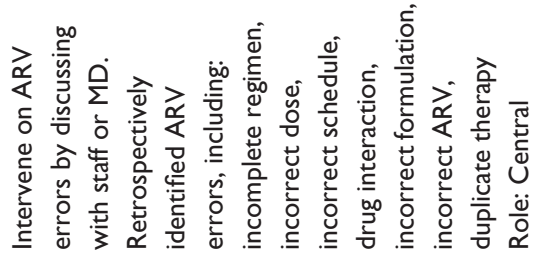

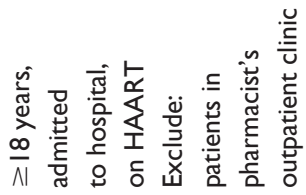

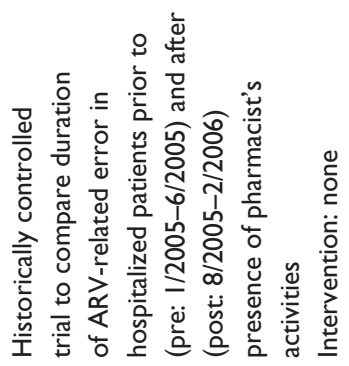

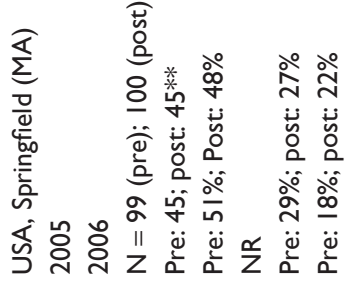

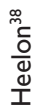




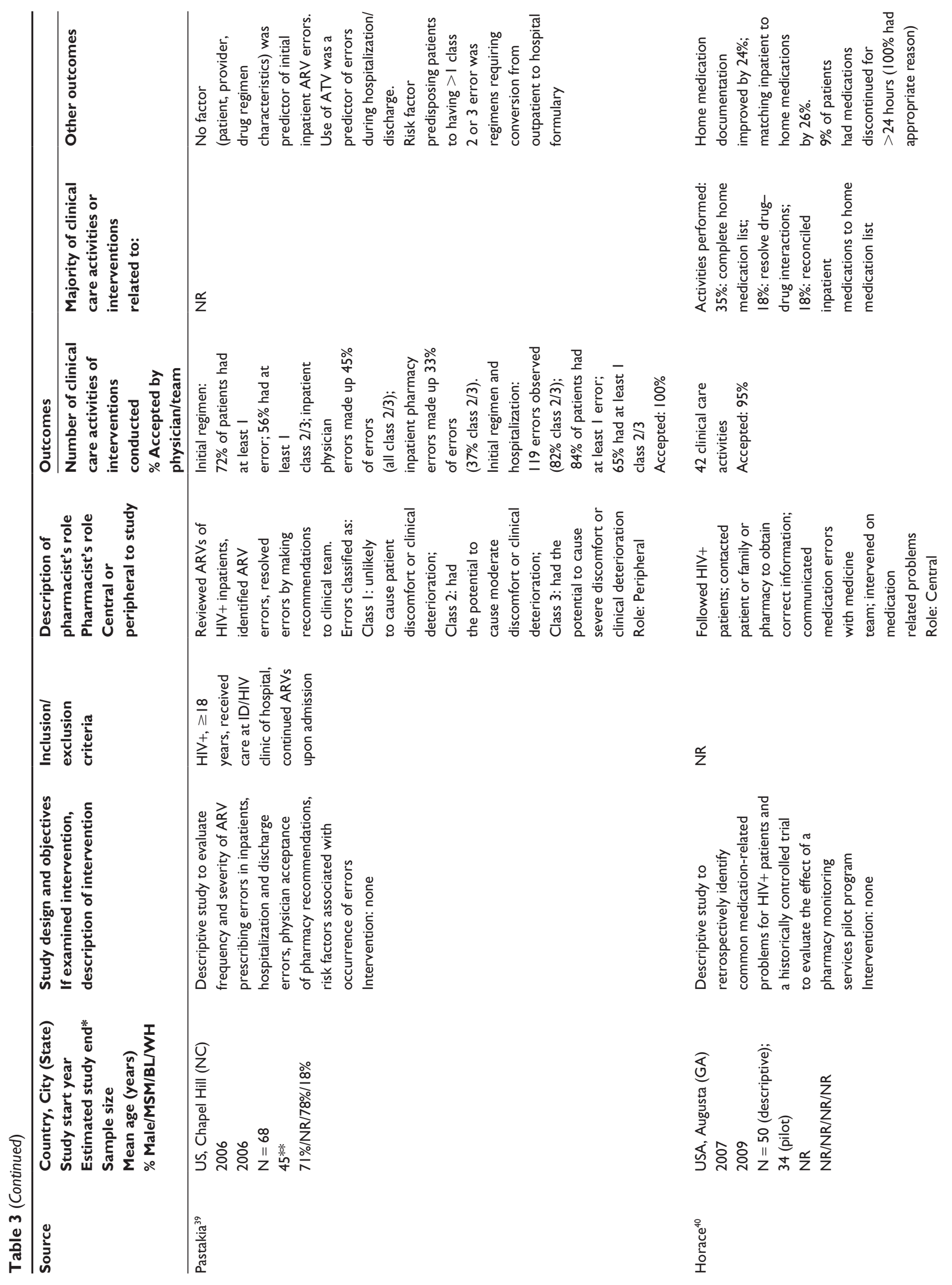



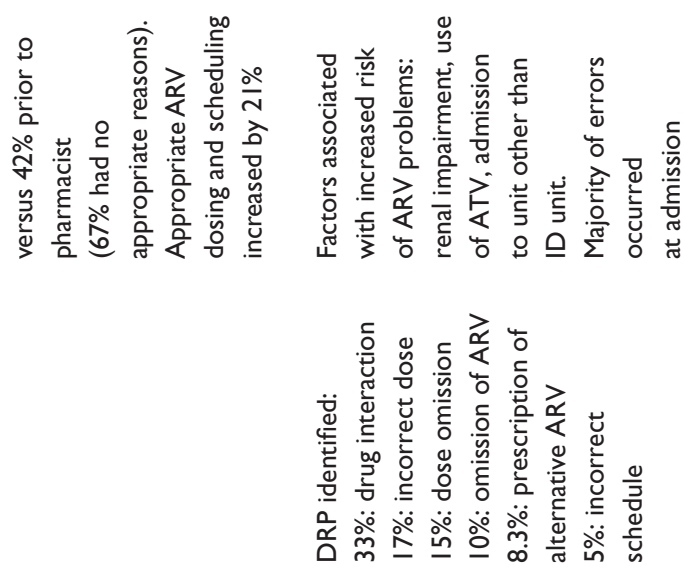

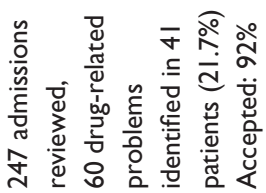

을

द्व

(5)

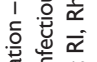

ปै

醇

层

垴

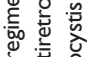

些

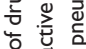

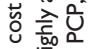

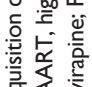

可福

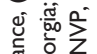

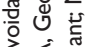

岁垈

U)

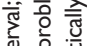

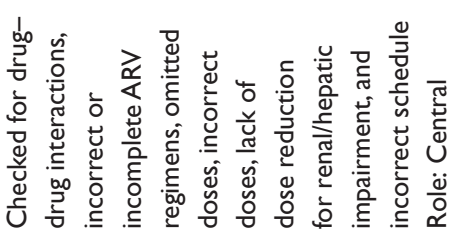

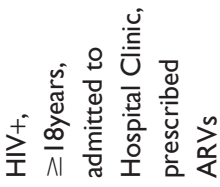

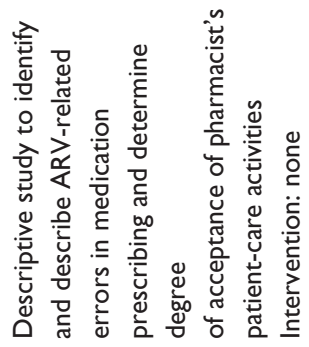

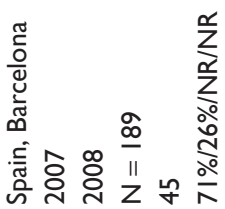

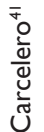

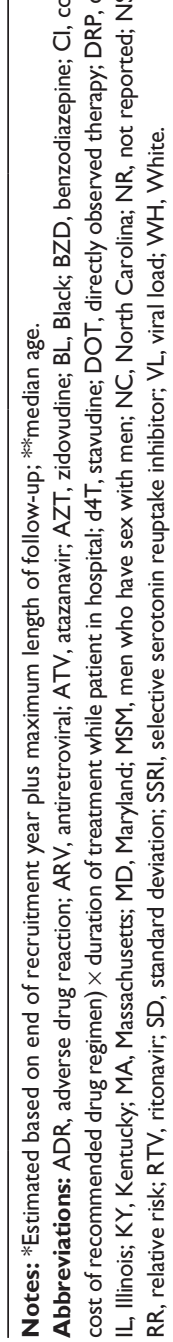


may have been due to lack of reporting of $\mathrm{CD}_{4}^{+}$cell count in many studies, insufficient duration of follow-up to observe substantial changes, the lack of an effect, or the more erratic nature of this outcome measure.

Several study-related factors limited the depth of our review. The most crucial limitation of several studies was the lack of reporting and/or adjustment for baseline demographics and confounders. The absence of reporting of clinical outcomes data in many studies and methodological constraints, such as reporting adherence as dichotomous or categorical variables or other methods, precluded a meta-analysis. Other common limitations included small sample size, short duration of study follow-up, incomplete description of the pharmacist's role or the complexity of multicomponent interventions, and the use of unconventional methods of adherence calculation. Lastly, as with any systematic review, there is the potential for positive publication bias influencing the aggregate results.

The reviewed studies provide a broad spectrum of HIV pharmacist activities. It is noteworthy that the majority of the reviewed studies were conducted in HIV ambulatory care or inpatient medical center settings. HIV pharmacists practicing in community pharmacies are increasingly called upon to provide ARV adherence training, patient education, and drug information, yet outcome data from such activities are not well-represented in the literature. This may be due to the under-recognized value of these services or the challenges associated with gaining combined access to laboratory medical record and community pharmacy data.

We found a plethora of descriptive studies on ARVrelated errors identified and resolved by the pharmacist and the degree of acceptance of pharmacist-related activities, as well as observational studies on the consistent evidence of a positive impact of HIV clinical pharmacists on ARV adherence. Therefore, future mixed methods research, including qualitative and quantitative studies should examine the pharmacist-patient relationship, focus on determining crucial pharmacist functions which have the most impact on adherence, and test these findings in randomized controlled trials with large sample sizes. Additionally, studies should examine cost-effectiveness of pharmacists (including cost savings associated with improvements in clinical markers, as well as other outcomes, such as reductions in extraneous physician visits, emergency room visits, length of hospitalization, medication errors, etc). Further research should also expand to include HIV pharmacist responsibilities that are beyond the "traditional" functions (ie, assessment of ARV accuracy, identification of drug interactions, adherence counseling, patient/provider education, etc). These roles may include the involvement of pharmacists in conducting clinical trials, performance of motivational interviewing, interpretation of drug resistance tests and prescription of ARVs, methods of tailoring adherence-enhancing tools based on individual reasons for nonadherence, and impact on HIV prevention (eg, through offering pre- or post-exposure prophylaxis).

It is evident in this review that research on the impact of pharmacists in HIV clinical care has evolved since the first reports in 1992. This progression includes the use of more sophisticated study designs and more complex research questions. Continued research on HIV pharmacists' impact on the clinical care of HIV-positive individuals is underway. In ClinicalTrials.gov and the US National Institute of Health Research Portfolio Online Reporting Tools database there are currently several ongoing studies examining the role of pharmacists in HIV clinical care. Four of these studies pertain to HIV prevention by assessing and expanding the pharmacist's role in services related to intravenous drug users purchasing syringes. ${ }^{42-45}$ Another project is assessing factors related to the receipt of pharmacist-provided adherence counseling and the impact of a counseling session based on the InformationMotivation-Behavioral Skills mode ${ }^{46,47}$ on HIV treatment outcomes. ${ }^{49} \mathrm{~A}$ randomized controlled trial is examining the impact of pharmacist care on ARV adherence. ${ }^{49}$ Lastly, economic outcomes of an intervention comparing methods of offering pharmacist services are also under study..$^{50}$

\section{Conclusion}

In conclusion, this systematic review provides support for the positive association between HIV pharmacist activities and improvements in ARV adherence and viral load suppression. HIV pharmacist functions were related to reductions in hospitalization, physician office visits, number of hospital days, visits to the emergency department, pill burden, and inappropriate discontinuation of outpatient medications; as well as improvements in inpatient documentation of home medications and accuracy of ARV dosing. A high percentage of pharmacists' recommendations were accepted by the physician or the health care team and the majority of the pharmacist's functions involved ARV dosing, detection of drug interactions or adverse drug reactions, provision of drug information, ARV adherence counseling, and instructing on the use of adherence-enhancing tools. This systematic review provides further evidence that, with the growing number of HIV-positive individuals worldwide, the increasing intricacies of HIV treatment options, and the 
shortage of physicians in resource limited settings, clinical pharmacists trained in HIV pharmacotherapy are invaluable resources and are essential members of the HIV multidisciplinary care team.

\section{Acknowledgments}

The authors thank Gloria Won for her assistance with the search strategies, conducting the electronic search, and creating our preliminary EndNote library. The project described was supported by NIH award numbers F32MH086323, K23MH087218, and K24MH087220. Jennifer Cocohoba received a one-time investigator initiated research grant from Gilead Sciences in 2009.

\section{Disclosure}

The authors report no conflicts of interests in this work.

\section{References}

1. Centers for Disease Control (CDC). Pneumocystis pneumonia - Los Angeles. MMWR Morb Mortal Wkly Rep. 1981;30(21):250-252.

2. Corelli RL, Guglielmo BJ, Kapusnik-Uner JE, McMaster JR, Greenblatt RM. Medication usage patterns in patients with human immunodeficiency virus infection: a comparison of patient-reported medication usage with medical chart review. DICP.1991;25(12):1374-1378.

3. Crawford NS. Organizing pharmacists to help fight AIDS. Am Pharm. 1991;NS31(3):44-47.

4. McKnight PT, Visconti JA, Gower RE, Para MF. Zidovudine: counseling strategies and Compliance. Am Pharm. 1991;31(10):38-43.

5. Weingarten CM, Freeland B. Pharmacist participation on an HIV resource team. Am J Health Syst Pharm. 1995;52(12):1282-1284.

6. Foisy MM, Tseng A, Blaikie N. Pharmacists' provision of continuity of care to patients with human immunodeficiency virus infection. Am J Health Syst Pharm. 1996;53(9):1013-1017.

7. Horberg MA, Hurley LB, Towner WJ, et al. WITHDRAWN: Determination of optimized multidisciplinary care team for maximal antiretroviral therapy adherence. J Acquir Immune Defic Syndr. January 30, 2012. [Epub ahead of print]

8. Lefebvre C, Manheimer E, Glanville J. Searching for studies. In: Higgins JPT, Green S, editors. Cochrane Handbook for Systematic Reviews of Interventions Version 5.1.0 (Updated March 2011). The Cochrane Collaboration; 2011.

9. Reeves BC, Deeks JJ, Higgins JPT, Wells GA. Including non-randomized studies. In: Higgins JPT, Green S, editors. Cochrane Handbook for Systematic Reviews of Interventions (Version 5.0.1): The Cochrane Collaboration; 2008.

10. Ostrop NJ, Gill MJ. Antiretroviral medication adherence and persistence with respect to adherence tool usage. AIDS Patient Care STDs. 2000;14(7):351-358.

11. McPherson-Baker S, Malow RM, Penedo F, Jones DL, Schneiderman N, Klimas NG. Enhancing adherence to combination antiretroviral therapy in non-adherent HIV-positive men. AIDS Care. 2000;12(4):399-404.

12. Mathews WC, Mar-Tang M, Ballard C, et al. Prevalence, predictors, and outcomes of early adherence after starting or changing antiretroviral therapy. AIDS Patient Care STDs. 2002;16(4):157-172.

13. Smith SR, Rublein JC, Marcus C, Brock TP, Chesney MA. A medication self-management program to improve adherence to HIV therapy regimens. Patient Educ Couns. 2003;50(2):187-199.

14. Castillo E, Palepu A, Beardsell A, et al. Outpatient pharmacy care and HIV viral load response among patients on HAART. AIDS Care. 2004;16(4):446-457.
15. Levy RW, Rayner CR, Fairley CK, et al for Melbourne Adherence Group. Multidisciplinary HIV adherence intervention: a randomized study. AIDS Patient Care STDs. 2004;18(12):728-735.

16. Gross R, Zhang Y, Grossberg R. Medication refill logistics and refill adherence in HIV. Pharmaco epidemiol Drug Saf. 2005;14(11): 789-793.

17. Rathbun RC, Farmer KC, Stephens JR, Lockhart SM. Impact of an adherence clinic on behavioral outcomes and virologic response in treatment of HIV infection: a prospective, randomized, controlled pilot study. Clin Ther. 2005;27(2):199-209.

18. Frick P, Tapia K, Grant P, Novotny M, Kerzee J. The effect of a multidisciplinary program on HAART adherence. AIDS Patient Care STDs. 2006;20(7):511-524.

19. Visnegarwala F, Rodriguez-Barradass MC, Graviss EA, Caprio M, Nykyforchyn M, Laufman L. Community outreach with weekly delivery of anti-retroviral drugs compared to cognitive-behavioural health care team-based approach to improve adherence among indigent women newly starting HAART. AIDS Care. 2006;18(4):332-338.

20. March K, Mak M, Louie SG. Effects of pharmacists' interventions on patient outcomes in an HIV primary care clinic. Am J Health Syst Pharm. 2007;64(24):2574-2578.

21. Horberg MA, Hurley LB, Silverberg MJ, Kinsman CJ, Quesenberry CP. Effect of clinical pharmacists on utilization of and clinical response to antiretroviral therapy. J Acquir Immune Defic Syndr. 2007;44(5): 531-539.

22. Hirsch JD, Rosenquist A, Best BM, Miller TA, Gilmer TP. Evaluation of the first year of a pilot program in community pharmacy: HIV/AIDS medication therapy management for Medi-Cal beneficiaries. J Manag Care Pharm. 2009;15(1):32-41

23. Pirkle CM, Boileau C, Nguyen VK, et al. Impact of a modified directly administered antiretroviral treatment intervention on virological outcome in HIV-infected patients treated in Burkina Faso and Mali. HIV Med. 2009;10(3):152-156.

24. Krummenacher I, Cavassini M, Bugnon O, Spirig R, Schneider MP, for Swiss HIV Cohort Study. Antiretroviral adherence program in HIV patients: a feasibility study in the Swiss HIV Cohort Study. Pharm World Sci. 2010;32(6):776-786. Epub September 23, 2010.

25. Ma A, Chen DM, Chau FM, Saberi P. Improving adherence and clinical outcomes through an HIV pharmacist's interventions. AIDS Care. 2010;22(10):1189-1194.

26. Hirsch JD, Gonzales M, Rosenquist A, Miller TA, Gilmer TP, Best BM. Antiretroviral therapy adherence, medication use, and health care costs during 3 years of a community pharmacy medication therapy management program for Medi-Cal beneficiaries with HIV/AIDS Journal Manag Care Pharm. 2011;17(3):213-223.

27. Krummenacher I, Cavassini M, Bugnon O, Schneider MP. An interdisciplinary HIV-adherence program combining motivational interviewing and electronic antiretroviral drug monitoring. AIDS Care. 2011;23(5):550-561.

28. Henderson KC, Hindman J, Johnson SC, Valuck RJ, Kiser JJ. Assessing the effectiveness of pharmacy-based adherence interventions on antiretroviral adherence in persons with HIV. AIDS Patient Care STDs. 2011;25(4):221-228. Epub Feburary 16, 2011.

29. Walji N, Beardsell A, Brown G. Pharmacists' activities in monitoring zidovudine therapy in an AIDS clinic. Can J Hosp Pharm. 1992;45(1): 29-32.

30. Geletko SM, Segarra M, Copeland DA, Teague AC. Pharmaceutical care for hospitalized HIV-infected patients compared to infectious diseases consult patients without HIV infection. BMJ Pharmacotherapy. 1996;2(1):45-57.

31. Bozek PS, Perdue BE, Bar-Din M, Weidle PJ. Effect of pharmacist interventions on medication use and cost in hospitalized patients with or without HIV infection. Am J Health Syst Pharm. 1998;55(11): 1151-1155.

32. Garey KW, Teichner P. Pharmacist intervention program for hospitalized patients with HIV infection. Am J Health Syst Pharm. 2000;57(24):2283-2284. 
33. Geletko SM, Poulakos MN. Pharmaceutical services in an HIV clinic. Am J Health Syst Pharm. 2002;59(8):709-713.

34. Segarra-Newnham M. Preventing medication errors with a pharmacy admission note for HIV-positive patients. Hosp Pharm. 2002;37(1): 34-37.

35. De Maat MMR, De Boer A, Koks CHW, et al. Evaluation of clinical pharmacist interventions on drug interactions in outpatient pharmaceutical HIV-care. J Clin Pharm Ther. 2004;29(2):121-130.

36. Foisy MM, Akai PS. Pharmaceutical care for HIV patients on directly observed therapy. Ann Pharmacother. 2004;38(4):550-556. Epub Feburary 27, 2004.

37. Sterling ES, Romanelli F, Martin CA, Hoven AD, Smith KM. Impact of a pharmacy-initiated HIV admission note on medication errors within an academic hospital. Hosp Pharm. 2005;40(10):874-881.

38. Heelon M, Skiest D, Tereso G, et al. Effect of a clinical pharmacist's interventions on duration of antiretroviral-related errors in hospitalized patients. Am J Health Syst Pharm. 2007;64(19):2064-2068.

39. Pastakia SD, Corbett AH, Raasch RH, Napravnik S, Correll TA. Frequency of HIV-related medication errors and associated risk factors in hospitalized patients. Ann Pharmacother. 2008;42(4):491-497.

40. Horace A, Philips M. Identification and prevention of antiretroviral medication errors at an academic medical center. Hosp Pharm. 2010;45(12):927-933.

41. Carcelero E, Tuset M, Martin M, et al. Evaluation of antiretroviralrelated errors and interventions by the clinical pharmacist in hospitalized HIV-infected patients. HIV Med. 2011;12(8):494-499. doi: 10.1111/j.1468-1293.2011.00915.x. Epub March 13, 2011.

42. Case PL. Feasibility of pharmacy-based HIV intervention among IDUs: 2 New England cities. National Institutes of Health Project Reporter (project number: R21DA025010); 2010. Available from: BioMedLib.com.
43. Fuller CM. Pharmacy referral intervention: IDU access to services. National Institutes of Health Project Reporter (project number: R01DA022144); 2010. Available from: BioMedLib.com.

44. Latkin CA. Feasibility of pharmacy-based HIV interventions among IDUs: India. National Institutes of Health Project Reporter (project number: R21DA024971); 2010. Available from: BioMedLib.com.

45. Pielemeier N. Feasibility of pharmacy-based HIV interventions among IDUs: Ha Giang, Vietnam. National Institutes of Health Project Reporter (project number: R21DA024986); 2010. Available from: BioMedLib.com.

46. Fisher JD, Fisher WA, Misovich SJ, Kimble DL, Malloy TE. Changing AIDS risk behavior: effects of an intervention emphasizing AIDS risk reduction information, motivation, and behavioral skills in a college student population. Health Psychol. 1996;15(2):114-123.

47. Amico KR, Toro-Alfonso J, Fisher JD. An empirical test of the information, motivation and behavioral skills model of antiretroviral therapy adherence. AIDS Care. 2005;17(6):661-673.

48. Cocohoba JM. Beyond pill-counting: effect of pharmacist counseling on antiretroviral adherence. National Institutes of Health Project Reporter (project number: K23MH087218); 2011. Available from: BioMedLib.com.

49. Hospital de Clinicas de Porto Alegre; Federal University of Rio Grande do Sul. Evaluation of effectiveness of pharmaceutical care on the adherence of HIV-positive patients to antiretroviral therapy (PC-HIV). In: ClinicalTrials.gov [website on the internet]. Bethesda, MD: US National Library of Medicine, 2009. Available from: clinicaltrials.gov/ct2/show/NCT00959361. NLM identifier: NCT00959361.

50. Wilson IB. Nudging doctors to collaborate with pharmacists to improve medication adherence. National Institutes of Health Project Reporter (project number: RC4AG039072); 2010. Available from: BioMedLib.com.
Patient Preference and Adherence

\section{Publish your work in this journal}

Patient Preference and Adherence is an international, peer-reviewed, open access journal focusing on the growing importance of patient preference and adherence throughout the therapeutic continuum. Patient satisfaction, acceptability, quality of life, compliance, persistence and their role in developing new therapeutic modalities and compounds to

\section{Dovepress}

optimize clinical outcomes for existing disease states are major areas of interest. This journal has been accepted for indexing on PubMed Central. The manuscript management system is completely online and includes a very quick and fair peer-review system. Visit http://www.dovepress.com/ testimonials.php to read real quotes from published authors. 